\title{
Efficacy and Mechanism of Panax Ginseng in Experimental Stroke
}

\author{
Lei Liu ${ }^{1}$, Gigi A. Anderson ${ }^{1}$, Tyler G. Fernandez ${ }^{1}$ and Sylvain Doré ${ }^{1,2 *}$ \\ ${ }^{1}$ Department of Anesthesiology, Center for Translational Research in Neurodegenerative Disease and McKnight Brain \\ Institute, University of Florida, Gainesville, FL, United States, ${ }^{2}$ Departments of Neurology, Psychiatry, Pharmaceutics, and \\ Neuroscience, University of Florida, Gainesville, FL, United States
}

\section{OPEN ACCESS}

Edited by:

Rubem C. A. Guedes, Federal University of Pernambuco,

Brazil

Reviewed by:

Maged Harraz,

Johns Hopkins University,

United States

Hak-Jae Kim

Soonchunhyang University,

South Korea

Guo-qing Zheng,

The Second Affiliated Hospital and Yuying Children's Hospital of Wenzhou

Medical University, China

*Correspondence: Sylvain Doré sdore@ufl.edu

Specialty section:

This article was submitted to Neuroenergetics, Nutrition and Brain

Health,

a section of the journal

Frontiers in Neuroscience

Received: 31 August 2018 Accepted: 13 March 2019

Published: 24 April 2019

Citation:

Liu L, Anderson GA, Fernandez TG and Doré S (2019) Efficacy and

Mechanism of Panax Ginseng in Experimental Stroke.

Front. Neurosci. 13:294. doi: 10.3389/fnins.2019.00294
Stroke is one of the leading causes of death and long-term disability worldwide. However, effective therapeutic approaches are still limited. The disruption of blood supply triggers complicated temporal and spatial events involving hemodynamic, biochemical, and neurophysiologic changes, eventually leading to pathological disturbance and diverse clinical symptoms. Ginseng (Panax ginseng), a popular herb distributed in East Asia, has been extensively used as medicinal and nutritional supplements for a variety of disorders worldwide. In recent years, ginseng has displayed attractive beneficial effects in distinct neurological disorders including stroke, involving multiple protective mechanisms. In this article, we reviewed the literature on ginseng studies in the experimental stroke field, particularly focusing on the in vivo evidence on the preventive or therapeutic efficacy and mechanisms of ginseng and ginsenosides in various stroke models of mice and rats. We also summarized the efficacy and underlying mechanisms of ginseng and ginsenosides on short- and long-term stroke outcomes.

Keywords: ginsenosides, global cerebral ischemia, intracerebral hemorrhage, middle cerebral artery occlusion, permanent MCAO, subarachnoid hemorrhage, transient MCAO

\section{INTRODUCTION}

Ginseng (Panax ginseng C. A. Meyer) has been extensively used as medicinal and nutritional supplements for a variety of disorders worldwide (Rastogi et al., 2014; Colzani et al., 2016). Asian ginseng has a history of herbal use over thousands of years, first described in the ancient Chinese pharmacopeia, Shen Nong Ben Cao Jing (300 BC-200 AD, also Divine Farmer's Classic of Materia Medica) (Unschuld, 1985; Yang and $\mathrm{Wu}, 2016$ ). It is one of the most highly regarded herbs in the Orient used to promote health, general body vigor, and to prolong life span. The Greek word "Panax" originates from the word "panacea," which means "cure all diseases," and true to its name, ginseng has been proven to have a wide variety of medicinal uses, including benefits in cardiovascular disorders (Karmazyn et al., 2011; Sun et al., 2016; Kim, 2018), aging-related disorders (Bjorklund et al., 2018), and others (Sotaniemi et al., 1995; An et al., 2011; Shergis et al., 2014; Zhang et al., 2017; Arring et al., 2018). In recent years, preclinical and clinical studies revealed that ginseng displayed attractive beneficial effects in multiple neurological disorders like stroke, hypertension, cancer, and maintenance of hemostasis in the immune system, involving multiple protective mechanisms (Lee et al., 2009; Im and Nah, 2013; Rastogi et al., 2014; Gonzalez-Burgos et al., 2015; Ong et al., 2015; Oh and Kim, 2016; Wang et al., 2016b; Kim et al., 2018).

Stroke is a leading cause of death and long-term disability worldwide (Feigin et al., 2017; Benjamin et al., 2018); however, effective therapies are limited (Feigin et al., 2016). The disruption of blood supply triggers complicated temporal and spatial events involving hemodynamic, 
biochemical, and neurophysiologic changes, eventually leading to pathological disturbance and diverse clinical symptoms (Lo et al., 2003; Iadecola and Anrather, 2011; Annunziato et al., 2013; Bernhardt et al., 2018). The severity and dynamic progression of brain injury depend on the degree of cerebral blood flow (CBF) interruption, lesion volume and site, duration of stroke, and the coexisting complications (Shen and Duong, 2008; Sun et al., 2014b; Fu et al., 2015; Ward, 2017). Accumulated evidence shows that oxidative stress and inflammation play key roles in the pathophysiology of stroke (Iadecola and Anrather, 2011; Li et al., 2011a; Carbone et al., 2015; Fu et al., 2015). Although the ginseng remedy has been widely applied to improve cardiac health and circulation, their studies in the stroke field are still limited (Gan and Karmazyn, 2018; Kim, 2018). Over the last decade, much promising advancements were made in the therapeutic effects of ginseng or ginsenosides on experimental stroke brain injury.

In this article, we reviewed the literature on ginseng and ginsenosides studies in the experimental stroke field, particularly focusing on the in vivo evidence in diverse stroke models of mice and rats. We summarized the efficacy of ginseng and ginsenosides on short- and long-term stroke outcomes, as well as the underlying molecular and cellular mechanisms. This review provides current understanding of the pharmacological benefits of ginseng that contribute to stroke prevention and recovery.

\section{PANAX GINSENG AND ITS ACTIVE CONSTITUENTS}

Two common products of ginseng are red ginseng, prepared by a process of steaming or heating, and dried white ginseng, prepared by air-drying after harvest (Wang et al., 2016a; He et al., 2018). Due to the presence of different active components, they have distinct pharmacodynamics profiles (Karmazyn et al., 2011). The major active components responsible for the pharmacological activities of ginseng are a group of unique triterpene glycosides or saponins called ginsenosides. The first attempt to isolate the active constituents of ginseng began many years ago, and the isolation of ginsenosides was started in 1963 (Shibata et al., 1963). To date, more than 150 ginsenosides have been isolated from ginseng, 40 of which have been found in Panax ginseng (Christensen, 2009).

Ginsenosides are divided into two different structural classes: (1) The 20(S)-protopanaxadiol (PPD) type that includes Ra1, Ra2, Ra3, Rb1, Rb2, Rb3, Rc, Rd, Rg3, Rh2, F2, and compound K; (2) The 20(S)-protopanaxatriol (PPT) type that includes Re, Rf, Rg1, Rg2, Rh1, and F1 (Baek et al., 2012). They share a four-ring hydrophobic steroid-like structure with sugar moieties, but differ in the carbohydrate moieties at C3, C6, and C20. Figure 1 shows the chemical structures of some of the most commonly studied ginsenosides. Quantitative and statistical analyses of the plasma indicate that PPD ginsenosides exhibit higher concentration and longer half-life than PPT ginsenosides (Zhang et al., 2014b). The peak concentrations of ginsenosides Rb1, Rb2/b3, Rc, Rd, Rg1, and Re are 55.32, 30.22, 21.42, 8.81, 7.15, $2.83 \mathrm{mg} / \mathrm{l}$, while their mean values of half-lives are $18.41,27.70,21.86,61.58,15.26$, and $2.46 \mathrm{~h}$, respectively.

Intact ginsenosides are absorbed only through the intestines with a very low absorption rate at $1-3.7 \%$. Most ginsenosides are metabolized in the stomach (acid hydrolysis) and/or intestine (bacterial hydrolysis) and transformed to other ginsenosides ( $\mathrm{Oh}$ and Kim, 2016). For instance, ginsenoside Rb1 is processed by gastric acid/intestinal microorganisms into smaller molecules, such as Rd, F2, and compound $\mathrm{K}$, and further into PPD. Similarly, ginsenoside $\mathrm{Rg} 1$ is converted into $\mathrm{Rh} 1$ and $\mathrm{F} 1$, and further into PPT, which is better absorbed in the gastrointestinal tract and therefore more bioactive than parent compounds. Collective evidences suggest that the metabolism and transformation of intact ginsenosides is a crucial process, influencing the bioavailability and potential health benefits of ginseng (Chen et al., 2008a).

\section{STROKE MODELS OF MICE AND RATS}

Stroke can be classified into two types: ischemic stroke and hemorrhagic stroke. In ischemic stroke patients, the middle cerebral artery (MCA) is the artery most often blocked. Accordingly, focal cerebral ischemia models (permanent or transient) that aim at MCA territory have been most widely used (Dorr et al., 2007; Mehta et al., 2007). In contrast, global cerebral ischemia occurs when cerebral blood flow (CBF) is disrupted throughout whole brain. Hemorrhagic stroke is a devastating stroke subtype with a high mortality rate within 1 month; it mainly includes intracerebral and subarachnoid hemorrhage (Maclellan et al., 2010; Ma et al., 2011; Leclerc et al., 2018).

(i) Permanent focal cerebral ischemia (pdMCAO and pMCAO): The MCA can be occluded at distal or relatively proximal site; consequently they are termed as pdMCAO or pMCAO. Comparably, the pdMCAO model generates a reproducible ischemic lesion that is mainly restricted in cortex region and leads to definable sensorimotor deficits. Because it closely mimics human ischemic stroke, it serves as one of the most useful stroke models, allowing to assess long-term recovery with high survival rate (Doyle and Buckwalter, 2014). pMCAO can be produced by the intraluminal suture MCAO.

(ii) Transient focal cerebral ischemia (tMCAO): The rodent MCAO with intraluminal suture is the most widely used animal stroke model, displaying reproducible MCA territory infarctions and allowing reperfusion by retracting the suture. Usually, MCAO generates ischemic infarct damage in the striatum, overlying frontal, temporal, parietal, and portions of cortex. Around 60 to $120 \mathrm{~min}$ of ischemia following MCAO is required to generate reproducible infarct volumes.

(iii) Global cerebral ischemia (GCI): Due to cardiac arrest, GCI results in delayed neuronal death in the hippocampal CA1 region and subsequent cognitive decline (Traystman, 2003; Tu et al., 2015; Ostrowski et al., 2016). The four-vessel occlusion $(4 \mathrm{VO})$ model provides a method of reversible 


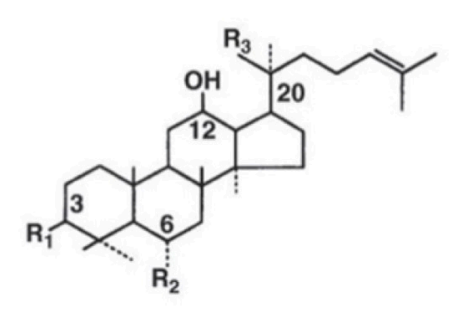

\begin{tabular}{|c|c|c|c|c|}
\hline & Ginsenoside & R1 & R2 & R3 \\
\hline \multirow{3}{*}{ PPD } & $\mathrm{Rb} 1$ & -O-Glu-Glu & $-H$ & -O-Glu-Glu \\
\hline & $\mathrm{Rg} 3$ & -O-Glu-Glu & $-H$ & $-\mathrm{OH}$ \\
\hline & $\mathrm{Rd}$ & -O-Glu-Glu & $-H$ & -O-Glu \\
\hline \multirow{2}{*}{ PPT } & Rg1 & $-\mathrm{OH}$ & -O-Glu & -O-Glu \\
\hline & $\mathrm{Re}$ & $-\mathrm{OH}$ & -O-Glu-Rha & -O-Glu \\
\hline
\end{tabular}

FIGURE 1 | Chemical structures of most commonly studied ginsenosides. Glu, glucose; Rha, rhamnose.

forebrain cerebral ischemia-reperfusion, whereas the twovessel (2VO) model was developed to characterize the incomplete ischemia (Traystman, 2003).

(iv) Cerebral hypoxia-ischemia (HI): $\mathrm{HI}$ is a transient unilateral cerebral ischemia model, which produces reproducible brain lesion in the ipsilateral hemisphere (Liu et al., 2019). Following the occlusion of one side of the common carotid artery and after a short recovery, the animal will be exposed to systemic hypoxia for no more than $1 \mathrm{~h}$.

(v) Intracerebral hemorrhage (ICH): $\mathrm{ICH}$ is a most devastating type of stroke without effective therapies. Two available models are used to mimic spontaneous intracerebral bleeding, either by the stereotactic injection of autologous blood or collagenase (Maclellan et al., 2010; Ma et al., 2016; Ahmad et al., 2017). Till now, no ginseng study has been performed in the ICH model.

(vi) Subarachnoid hemorrhage (SAH): SAH claims one of the highest rates of mortalities and morbidities. None of therapeutic options has effectively to reduce mortality rate in a clinical setting. Rodent models have been predominantly made by approaches involving intravascular perforation of a vessel in the circle of Willis or direct injection of blood into the cisterna magna or prechiasmatic cistern (Leclerc et al., 2018).

\section{Therapeutic Effects of Panax Ginseng on Stroke Outcomes: The in vivo Evidence}

Multiple administration strategies of ginseng have been employed in the experimental stroke studies, including mice or rats with different genetic backgrounds, pre-treatment or posttreatment, administration routes, dosage range and duration, and various histological and neurobehavioral stroke outcomes. Infarct volume is designed to evaluate the temporal evolution of stroke damage that can be easily measured with different techniques. Neurobehavioral assessment is an essential measure of stroke outcome since functional recovery is universally used as a primary endpoint in clinical trials. Both histological and neurobehavioral measurements are considered as pivotal components for examining efficacy of potential therapeutics in the translational stroke research field. Here, we outlined the short-term (usually referring to the acute stage of recovery following stroke, about $1-3 \mathrm{~d}$ ) and long-term (usually referring to $3 \mathrm{~d}$ to weeks or months following stroke) effects of ginseng and ginsenosides on stroke outcomes. Table 1 summarized the details of these studies.

\section{Red Ginseng}

The standard extracts of red ginseng (such as Korean red ginseng, KRG) are manufacture by the traditional preparation method (by a steaming or heating process) and contain most of the primary effective components, coordinately controlling the pharmacological efficacy in the body (Lee et al., 2015; Wang et al., 2016a). Many are converted from the major ginsenosides $\mathrm{Rb} 1, \mathrm{Rb} 2, \mathrm{Rc}, \mathrm{Rd}, \mathrm{Rg} 1$, and Re (Lee et al., 2015). The therapeutic efficacy of KRG on ischemic brain damage, at the dosage of $100-360 \mathrm{mg} / \mathrm{kg} / \mathrm{d}$ for $7-14 \mathrm{~d}$, has been revealed in permanent and transient cerebral ischemia models by several groups. In the pdMCAO mouse model, KRG pretreatment prevented the acute enlargement of ischemic brain lesion $(36.37 \pm 7.45 \%$ on d3) and the definable sensorimotor deficits indicated by optimized cylinder and corner tests, and such functional benefits extended over 28d (Liu et al., 2018b). KRG pretreatment also reduced the infarct volume at $24 \mathrm{~h}$ and improved the coordinated motor deficits, indicated by the rotarod test, at 3 and $7 \mathrm{~d}$ after MCAO (1 h) (Cheon et al., 2013). Recently, it was reported that pretreatment with Ginseng elicited robust neuroprotection against the deterioration of acute cerebral hypoxia-ischemia damage in an Nrf2-dependent manner, evidenced by the reductions of neurological deficits and brain infarction and edema at 6 h, 1 and 3d after HI (Liu et al., 2019). Such beneficial outcomes could be associated with the enhanced expression levels of Nrf2 target antioxidant proteins and anti-inflammation mediators. Meanwhile, KRG post-treated rats showed significant improvement in the neurological deficits for $7 \mathrm{~d}$ indicated by the modified neurological deficits score (NDS) and corner test, as well as the infarct volume at $7 \mathrm{~d}$, following ischemia-reperfusion injury after MCAO (2 h) (Lee et al., 2011; Ban et al., 2012). In addition, ethanolic $\mathrm{P}$. ginseng extracts post-treatment was reported to reduce rat hippocampal CA1 neuronal death $7 \mathrm{~d}$ after global cerebral ischemic injury (Kim et al., 2009), further supporting the beneficial role of KRG in ischemic stroke.

\section{Ginsenoside Rb1}

Ginsenoside Rb1 (Rb1) is a representative component of Panax genus, including Panax ginseng (Asian ginseng), Panax quinquefolius (American ginseng), and Panax notoginseng 


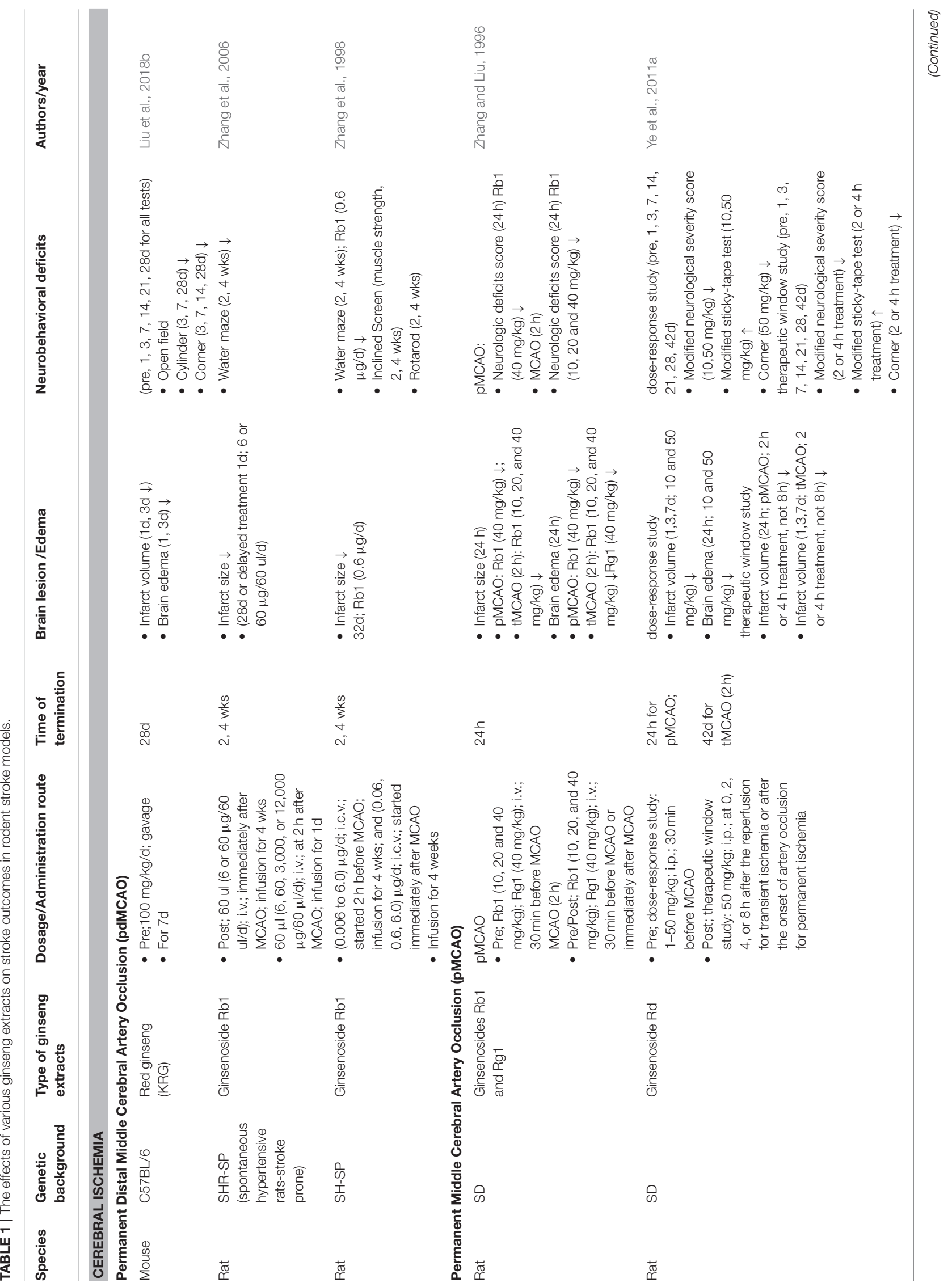




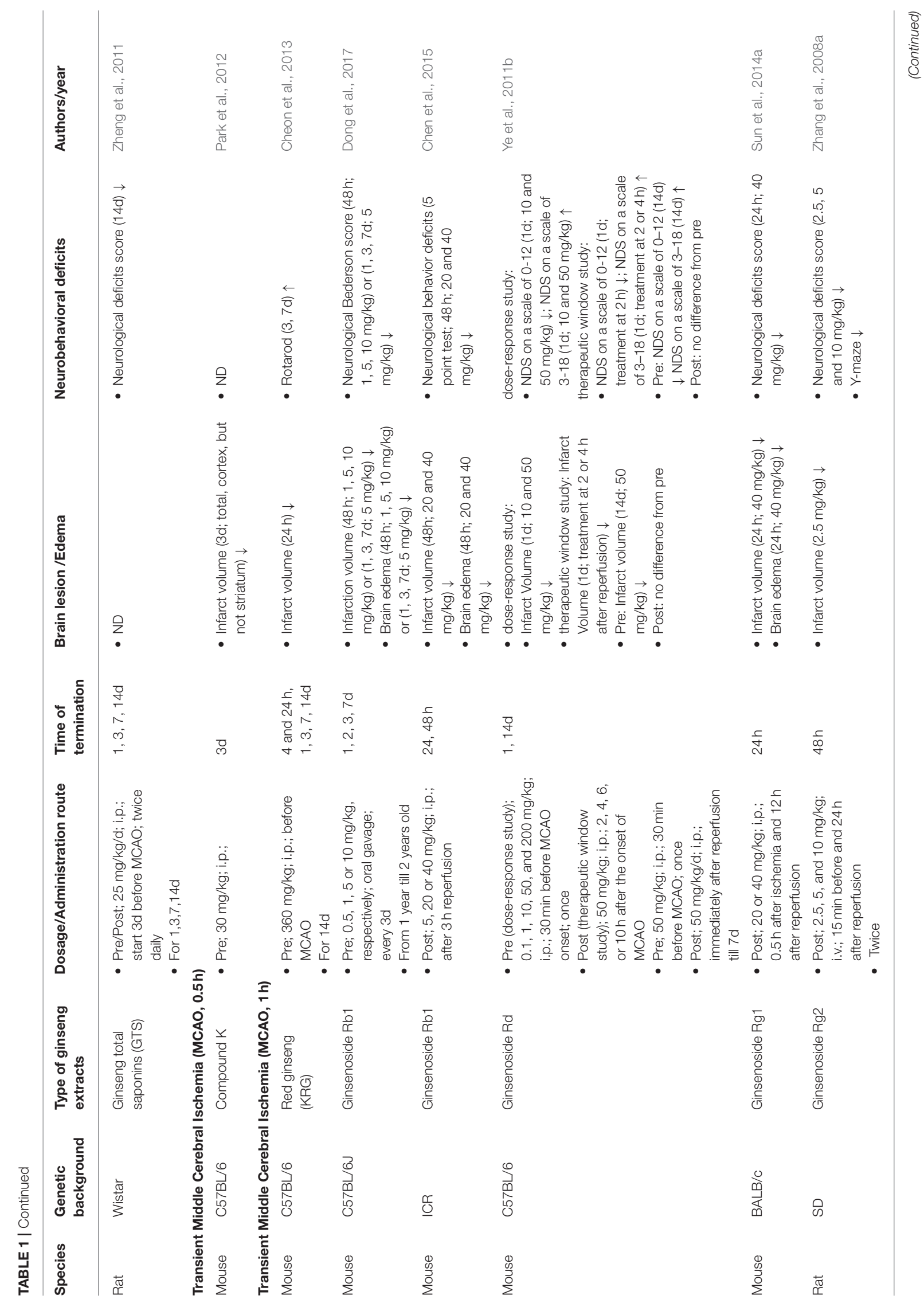




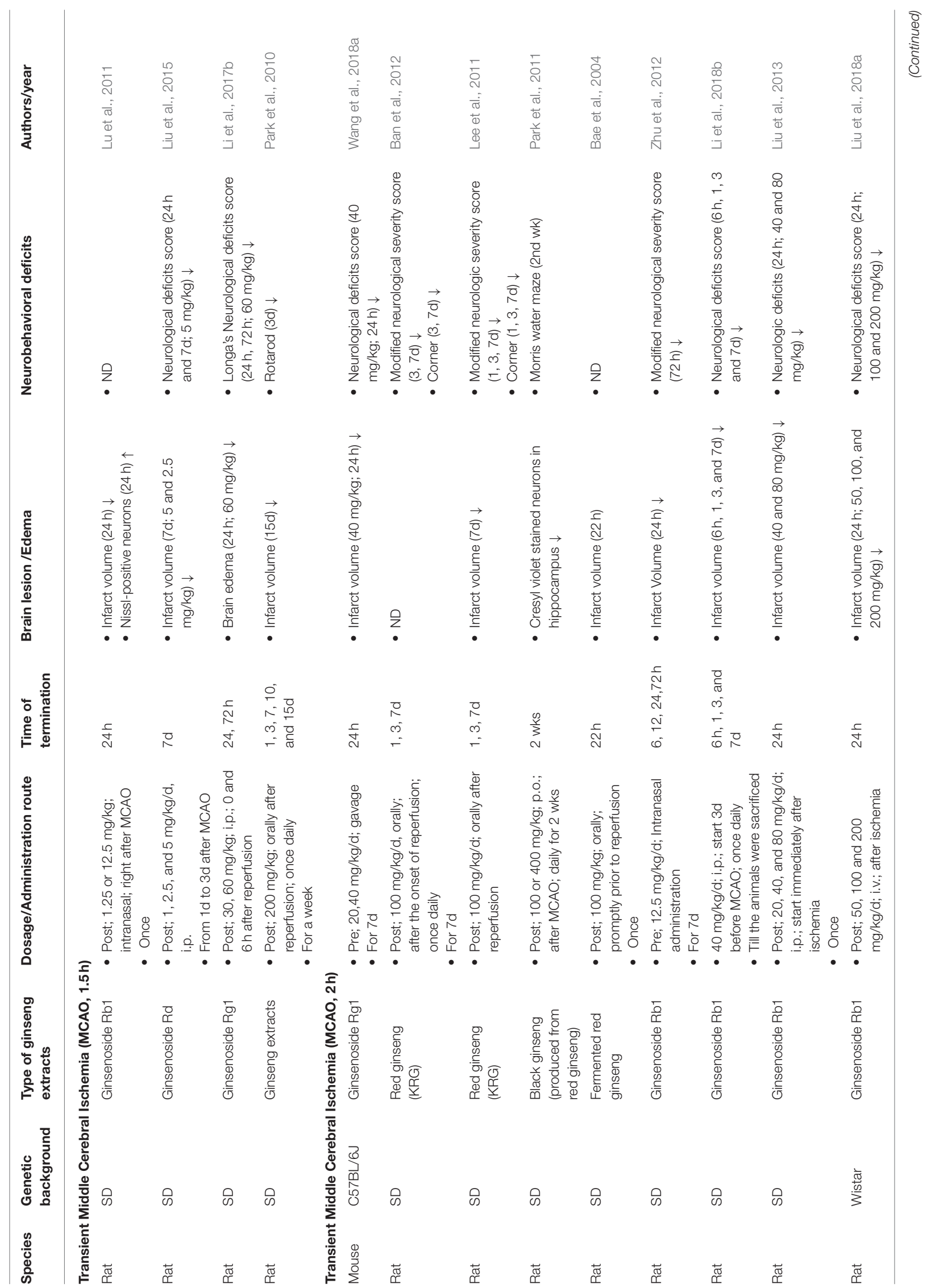




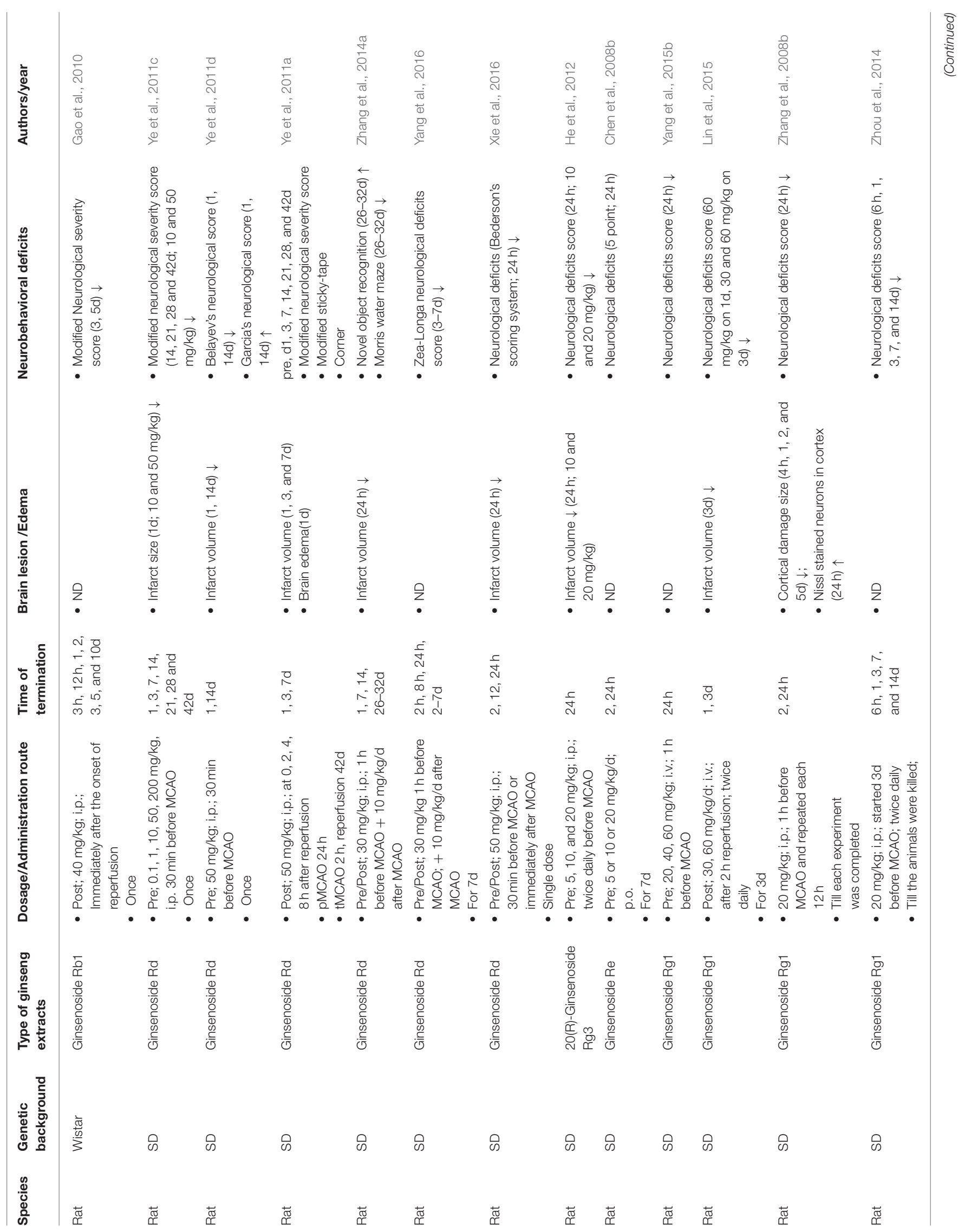




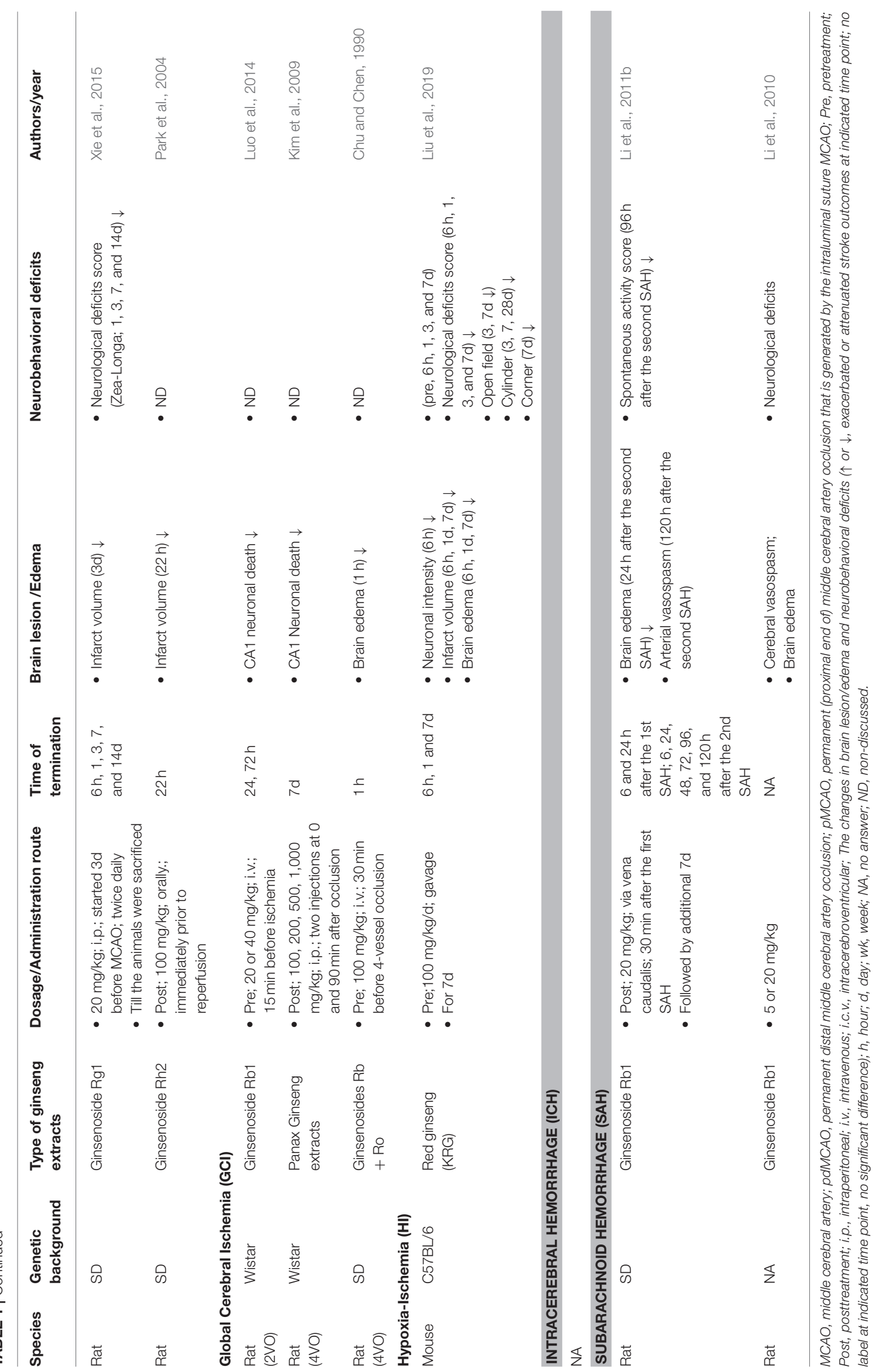


(Ahmed et al., 2016), which has exhibited potent efficacy on cardiovascular disorders like myocardial Ischemia-reperfusion Injury (Zheng et al., 2017). In pdMCAO rats with stroke-prone spontaneous hypertension, $\mathrm{Rb} 1$ pretreatment by intravenous infusion ameliorated ischemia-induced place navigation disability at 2 and 4 weeks evidenced by the water maze test, reduced muscle strength deficit in the inclined screen test, impaired coordinated four-leg movements function in the rotarod test, and decreased the volume of the cortical infarct lesion at 28 and 32d after ischemia (Zhang et al., 1998, 2006). In pMCAO rats, Rb1 pretreatment reduced acute ischemic brain damage in infarct volume and overall neurological deficits $24 \mathrm{~h}$ after ischemia (Zhang and Liu, 1996). In MCAO (1-2 h) rats, $\mathrm{Rb} 1$ pre- or post-treatment significantly reduced acute brain lesion, evidenced by infarct volume at $24 \mathrm{~h}$ (Lu et al., 2011; Zhu et al., 2012) or $48 \mathrm{~h}$ (Chen et al., 2015; Dong et al., 2017), brain edema (Dong et al., 2017) at $48 \mathrm{~h}$, and neurobehavioral deficits indicted by the overall neurological deficits score at $48 \mathrm{~h}$ (Chen et al., 2015; Dong et al., 2017), 72 h (Gao et al., 2010; Zhu et al., 2012), and 5d (Gao et al., 2010) after reperfusion onset. In GCI (2VO) rats, Rb1 pretreatment protected against hippocampal CA1 neuronal death at the acute stage of ischemia (Luo et al., 2014). Besides its favorable role in ischemic stroke, Rb1 also exhibited extensive neuroprotection in subarachnoid hemorrhage brain damage. Rb1 treatment dramatically reduced brain edema, cerebral vasospasm, and neurological deficits including spontaneous activity (Li et al., 2010, 2011b), indicating the extensive benefits to stroke outcomes.

\section{Ginsenoside Rg1}

Ginsenosides Rb1 and $\operatorname{Rg} 1$ (Rg1) are the most abundant ginsenosides in ginseng roots, exhibiting pharmacological properties in multiple neurological conditions (Gao et al., 2017b; Song et al., 2017; Mohanan et al., 2018). Multiple studies have revealed the preventive and therapeutic efficacy of $\operatorname{Rg} 1$ on acute ischemia-reperfusion brain damage and long-term recovery in MCAO (1-2h) of mice and rats. Rb1 pre- or post-treatment reduced the infarct volume at $24 \mathrm{~h}$ (Sun et al., 2014a; Li et al., 2017b; Wang et al., 2018a) and 3d (Lin et al., 2015) and brain edema at $24 \mathrm{~h}$, and attenuated overall neurological deficits at $6 \mathrm{~h}$ (Zhou et al., 2014), 24h (Zhang et al., 2008b; Sun et al., 2014a; Zhou et al., 2014; Lin et al., 2015; Xie et al., 2015; Yang et al., 2015b; Li et al., 2017b; Wang et al., 2018a) and 3d (Zhou et al., 2014; Xie et al., 2015) following MCAO (1-2 h). The neurobehavioral protection was also observed at late stage of stroke, evidenced by the reduced neurological deficits at 7 and 14d after MCAO (1-2 h) (Zhou et al., 2014; Xie et al., 2015).

\section{Ginsenoside Rd}

Similar as the ginseng extracts above, ginsenoside Rd (Rd) is another important ingredient of ginsenosides and widely investigated in the stroke field (Ye et al., 2013; Nabavi et al., 2015). In pdMCAO model mice, either pre-treatment or post-treatment of Rd prevented acute ischemic brain injury and promoted the long-term histological and neurobehavioral recovery, evidenced by the reduction of infarct volume at 1,3, and $7 \mathrm{~d}$ and neurological deficits score, sticky-tape test, and corner test over $42 \mathrm{~d}$ after ischemia (Ye et al., 2011a). This benefit was also observed in ischemia-reperfusion rodent models. In MCAO $(1.5 \mathrm{~h})$ model rats, $\mathrm{Rd}$ post-treatment exhibited sustained neuroprotection against ischemic brain damage, indicated by the reduced neurological deficits at 1 and $7 \mathrm{~d}$ and infarct volume at $7 \mathrm{~d}$ after the onset of reperfusion (Liu et al., 2015). In MCAO (2 h), several studies showed that Rd treatment alleviated ischemia-reperfusion induced infarct volume at $24 \mathrm{~h}$ (Ye et al., 2011a,c,d; Zhang et al., 2014a; Xie et al., 2016), 3d, 7d (Ye et al., 2011a), and 14d (Ye et al., 2011d), and reduced overall neurological deficits at 142d (Ye et al., 2011a,c,d; Zhang et al., 2014a; Xie et al., 2016; Yang et al., 2016).

\section{Ginsenoside Rg3}

Ginsenoside $\operatorname{Rg} 3$ ( $\mathrm{Rg} 3$ ) is abundantly present in red ginseng preparation, which is highly known for its anticancer effects (Sun et al., 2017; Mohanan et al., 2018). A report showed that Rg3 pretreatment reduced ischemia-reperfusion injury, indicated by reduced infarct volume and overall neurological deficits score at $24 \mathrm{~h}$ after MCAO (2 h) (He et al., 2012).

\section{Ginsenoside Re}

Ginsenoside $\operatorname{Re}(\mathrm{Re})$ is a major ginsenoside and important ingredient in ginseng leaf, berry, and root, exhibiting multiple pharmacological activities via different mechanisms (Peng et al., 2012). Re protected rats against acute brain lesion, indicated by the reduction of infarct volume at $24 \mathrm{~h}$ after MCAO $(2 \mathrm{~h})$ (Chen et al., 2008b).

\section{Ginsenoside Rh2}

Ginsenoside Rh2 (Rh2), an important ginsenoside (Smith et al., 2014), was reported to reduce the acute ischemia-reperfusion damage indicated by reduced infarct volume at $22 \mathrm{~h}$ after MCAO (2 h) (Park et al., 2004).

\section{Compound K}

Compound $\mathrm{K}$ is one of the major metabolites of ginseng, exhibiting a variety of pharmacological activities, including antiinflammatory, antitumor, and other effects (Shin et al., 2015; Yang et al., 2015a). Compound K pretreatment significantly reduced the infarct volume (hemisphere, cortex, but not striatum) of ischemic brain after MCAO (0.5 h) (Park et al., 2012).

\section{Black Ginseng}

Black ginseng is a more recent type of processed ginseng with a unique components profile, implying potent in vitro and in vivo pharmacological activities (Liu et al., 2010; Jin et al., 2015). A study showed that 2 weeks' black ginseng post-treatment improved the impairment of learning and memory in rats, indicated by the Morris water maze 2 weeks after MCAO ( $2 \mathrm{~h}$ ) (Park et al., 2011).

\section{Ginseng Total Saponins}

Ginsenosides (ginseng total saponins, GTS) may be mainly responsible for the pharmacological effects of ginseng. GTS treated rats have better neurological scores compared with those in control group at 14d after pMCAO (Zheng et al., 2011). 


\section{Ginsenosides Rb and Ro Mixture}

It was reported that pretreatment with ginsenosides $\mathrm{Rb}$ and Ro mixture (which was hard to purify due to similar polarity), markedly reduced ischemic brain edema in rats at $1 \mathrm{~h}$ following GCI (4VO) (Chu and Chen, 1990).

\section{Fermented Red Ginseng}

Fermented red ginseng was reported to be prepared from red ginseng extract, and the primary components were compound $\mathrm{K}>$ ginsenoside $\operatorname{Rg} 3>$ or $=$ ginsenoside $\mathrm{Rh} 2$ (Bae et al., 2004). It was shown to protect against ischemic brain injury, indicated by the significant reduction of infarct volume after $22 \mathrm{~h}$ of reperfusion.

\section{NEUROPROTECTIVE MECHANISMS OF PANAX GINSENG IN STROKE}

The discovery of the beneficial effects of ginseng or ginsenosides on ischemic and hemorrhagic stroke has spurred interest in their mechanisms of action. Multiple potential neuroprotective mechanisms were evaluated during the studies (Table 2).

\section{Anti-oxidative Stress}

Redox homeostasis in the cell is maintained by the counterbalance between reactive oxygen and nitrogen species (ROS/RNS) generation and the antioxidant defense system (Lin and Beal, 2006; Ma, 2013). Oxidative stress is a result of imbalance between the ROS/RNS and the antioxidant defense system. ROS/RNS are constantly produced by oxygen metabolism in accordance with the rate of oxidant formation and elimination, most of which comes from mitochondria (Balaban et al., 2005). Under normal conditions, only $1-2 \%$ of molecular oxygen is converted into superoxide radicals (Orrenius et al., 2007; Drummond et al., 2011) and then removed by the potent and extensive antioxidant system. However, under stress conditions like stroke attack, the overproduction of ROS and the reduced antioxidant capacity result in oxidative damage to DNA, RNA, lipids, and other cell components, eventually leading to cell death. The central nervous system (CNS) is typically vulnerable to oxidative stress as it consumes a higher amount of oxygen and has a lower level of endogenous antioxidant defense capacity than other organs (Sims and Muyderman, 2010; Chen et al., 2011; Sinha and Dabla, 2015). The rapid increase in the production of ROS/RNS immediately following stroke overwhelms the antioxidant defense system, damaging cellular macromolecules which leads to apoptosis, autophagy, and necrosis (Rodrigo et al., 2013). Moreover, the restoration of blood flow further increases the tissue oxygenation level and initiates a second burst of ROS/RNS overproduction, triggering reperfusion injuries (Sims and Muyderman, 2010; Rodrigo et al., 2013). Given that oxidative stress occurs early and acts causally in stroke pathogenesis (Chen et al., 2011), therapies targeting basic oxidative processes, such as free-radical generation or specific antioxidants that interact with stroke-related proteins, hold great promise (Becerra-Calixto and Cardona-Gomez, 2017; Bhatti et al., 2017).
Accumulated evidence demonstrated the beneficial efficacy of ginseng against various CNS diseases, mainly owing to its anti-oxidative and anti-inflammation properties (GonzalezBurgos et al., 2015; Ahmed et al., 2016; Lee et al., 2017). Several studies supported that, associated with their benefits on stroke outcomes, ginseng, or ginsenosides have the antioxidant potential against stroke damage by scavenging overproduced ROS/RNS via modulating endogenous antioxidant defense system. KRG attenuated the oxidative damages indicated by the reduced levels of 8-hydroxyguanosine (8-OHG) (Cheon et al., 2013), a biomarker of oxidative DNA damage, and lipid peroxidation (Ban et al., 2012) and the increased antioxidant related protein levels in superoxide dismutase 2 (SOD2), glutathione peroxidase 1 (Gpx1), heme oxygenase 1 (HO1), and $\mathrm{NAD}(\mathrm{P}) \mathrm{H}$ quinone dehydrogenase 1 (NQO1) (Liu et al., 2018b, 2019) compared to controls. Mitochondrial SOD2 is one critical component of the antioxidant system, accounting for the removal of superoxide ions in the mitochondria (Flynn and Melov, 2013). GPx is another key antioxidant enzyme that catalyzes the reduction of lipid peroxides and hydroperoxide to non-toxic species. Superoxide in the mitochondrial matrix is metabolized to hydrogen peroxides by SOD2 and decomposed to water by GPx (Ghosh et al., 2011). HO1, an inducible enzyme, has emerged as a major protective mechanism against oxidative stress (Zeynalov et al., 2009). In addition, these findings above are also supported by the results in GCI model (Luo et al., 2014). Rb1 was shown to have neuroprotective effects on brain damage by anti-oxidant activity, indicated by the levels of glutathione (GSH), MDA, nitric oxide (NO), nicotinamide adenine dinucleotide phosphate (NADPH) oxidase (NOX) expression and NADPH oxidase activity (Dong et al., 2017). Rg1 increased the activity or content of antioxidant enzymes SOD and catalase (CAT) (Li et al., 2017b), as well as HO1 (Yang et al., 2015b), contributing to the histological and functional benefits after stroke. Rd treated animals exhibited a reduced level in free radical generation revealed by microdialysis, oxidative DNA damage (8-OHG), oxidative proteins carbonyl and advanced glycosylation end products (AGEs), lipid peroxidation [malondialdehyde (MDA) and 4-hydroxynonenal formations (4HNE)] following MCAO (Ye et al., 2011c). Rd administration also reduced mitochondrial DNA (mtDNA) and nuclear DNA (nDNA) damages, which contributed to an improvement in survival rate and neurological function (Yang et al., 2016). It was observed that Re significantly ameliorated lipid peroxidation by raising the activities of SOD and GSH-Px, and reduced the content of MDA in rat brains protecting against cerebral ischemia-reperfusion injury (Zhou et al., 2006), which was supported by another Re study in MCAO (Chen et al., 2008b).

In recent years, fundamental progress in the oxidative stress research field was the discovery of transcriptional factor Nrf2/antioxidant response element (ARE) pathway, which is the master regulator of redox hemostasis by tightly controlling multiple ARE-driven antioxidant proteins likeNQO1 and HO1 (Cuadrado et al., 2018; Raghunath et al., 2018; Yamamoto et al., 2018). In response to stress conditions or $\mathrm{Nrf2}$ 
TABLE 2 | The putative neuprotective mechanisms of Panax ginseng in experimental stroke.

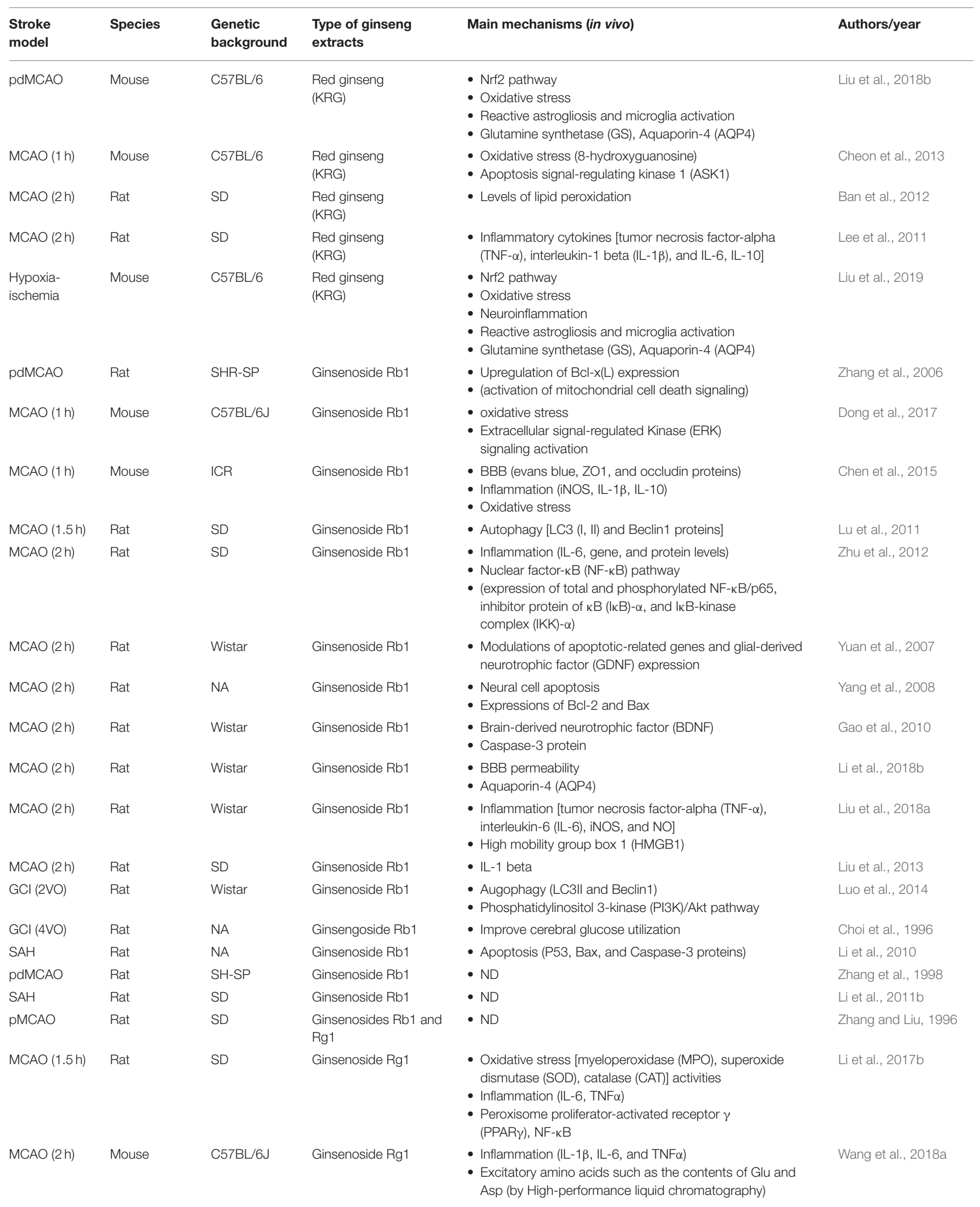


TABLE 2 | Continued

\begin{tabular}{|c|c|c|c|c|c|}
\hline $\begin{array}{l}\text { Stroke } \\
\text { model }\end{array}$ & Species & $\begin{array}{l}\text { Genetic } \\
\text { background }\end{array}$ & $\begin{array}{l}\text { Type of ginseng } \\
\text { extracts }\end{array}$ & Main mechanisms (in vivo) & Authors/year \\
\hline MCAO (2h) & Rat & SD & Ginsenoside Rg1 & $\begin{array}{l}\text { - Apoptosis (TUNEL) } \\
\text { - Extracellular signal-regulated kinase 1/2 (ERK1/2), } \\
\text { phosphorylated extracellular signal-regulated kinase 1/2 } \\
\text { (p-ERK1/2), c-Jun N-terminal kinases (JNK), and } \\
\text { phosphorylated c-Jun N-terminal kinase (p-JNK) }\end{array}$ & Wang et al., 2013a \\
\hline $\mathrm{MCAO}(2 \mathrm{~h})$ & Rat & SD & Ginsenoside Rg1 & - Metabolic regulation & Lin et al., 2015 \\
\hline MCAO (2h) & Rat & SD & Ginsenoside Rg1 & $\begin{array}{l}\text { - } \mathrm{Ca}^{2+} \text { influx through } \mathrm{NMDA} \text { receptors and L-type } \\
\text { voltage-dependent } \mathrm{Ca}^{2+} \text { channels }\end{array}$ & Zhang et al., 2008b \\
\hline MCAO (2h) & Rat & SD & Ginsenoside Rg1 & $\begin{array}{l}\text { - } \text { BBB integrity } \\
\text { - matrix metalloproteinases (MMPs) }\end{array}$ & Wang et al., 2013b \\
\hline MCAO (1 h) & Mouse & $\mathrm{BALB} / \mathrm{c}$ & Ginsenoside Rg1 & $\bullet N D$ & Sun et al., 2014a \\
\hline MCAO (1 h) & Mouse & C57BL/6 & Ginsenoside Rd & $\begin{array}{l}\text { - Mitochondrial dysfunction } \\
\text { - Antioxidant activities }\end{array}$ & Ye et al., 2011b \\
\hline MCAO (1.5 h) & Rat & SD & Ginsenoside Rd & - Neurogenesis & Liu et al., 2015 \\
\hline MCAO (2h) & Rat & SD & Ginsenoside Rd & $\begin{array}{l}\text { - Early oxidative damage and sequential inflammatory } \\
\text { response (Free radical generation (microdialysis), oxidative } \\
\text { DNA damage (8-hydroxy-deoxyguanosine), oxidative } \\
\text { protein (protein carbonyl and advanced glycosylation end } \\
\text { products), lipid peroxidation (the malondialdehyde and } \\
\text { 4-hydroxynonenal formations) }\end{array}$ & Ye et al., 2011c \\
\hline MCAO $(2 \mathrm{~h})$ & Rat & SD & Ginsenoside Rd & 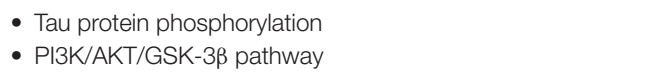 & Zhang et al., 2014a \\
\hline MCAO (2h) & Rat & SD & Ginsenoside Rd & $\begin{array}{l}\text { - Mitochondrial DNA (mtDNA) and nuclear DNA (nDNA) } \\
\text { damages }\end{array}$ & Yang et al., 2016 \\
\hline MCAO (2h) & Rat & SD & Ginsenoside Rd & $\begin{array}{l}\text { - The phosphorylation of the NMDAR 2B subunit (NR2B } \\
\text { subunit) }\end{array}$ & Xie et al., 2016 \\
\hline PMCAO & Rat & SD & Ginsenoside Rd & - ND & Ye et al., 2011a \\
\hline MCAO (1.5 h) & Rat & SD & Ginsenoside Rd & - ND & Zhang et al., 2012 \\
\hline MCAO (2 h) & Rat & Wistar & Ginsenoside Re & $\begin{array}{l}\text { - Oxidative stress [lipid peroxidation: malondiadehyde (MDA) } \\
\text { formation], superoxide dismutase (SOD) and glutathion } \\
\text { peroxidase (GSH-Px)] }\end{array}$ & Zhou et al., 2006 \\
\hline MCAO (2h) & Rat & SD & Ginsenoside Re & - Oxidative stress (MDA) & Chen et al., 2008b \\
\hline MCAO (2 h) & Rat & SD & Ginsenoside Rh2 & - ND & Park et al., 2004 \\
\hline MCAO (2 h) & Rat & SD & 20(R)-Ginsenoside Rg3 & $\begin{array}{l}\text { - Apoptosis (TUNEL) } \\
\text { - Calpain I and caspase-3 }\end{array}$ & He et al., 2012 \\
\hline
\end{tabular}


TABLE 2 | Continued

\begin{tabular}{|c|c|c|c|c|c|}
\hline $\begin{array}{l}\text { Stroke } \\
\text { model }\end{array}$ & Species & $\begin{array}{l}\text { Genetic } \\
\text { background }\end{array}$ & $\begin{array}{l}\text { Type of ginseng } \\
\text { extracts }\end{array}$ & Main mechanisms (in vivo) & Authors/year \\
\hline MCAO (0.5 h) & Mouse & C57BL/6 & Compound $\mathrm{K}$ & $\begin{array}{l}\text { - Inflammation } \\
\text { - Microglial activation }\end{array}$ & Park et al., 2012 \\
\hline MCAO (1.5 h) & Rat & SD & $\begin{array}{l}\text { Black ginseng } \\
\text { (produced from red } \\
\text { ginseng) }\end{array}$ & - ND & Park et al., 2011 \\
\hline $\mathrm{GCl}(4 \mathrm{VO})$ & Rat & Wistar & Panax Ginseng extracts & - Oxidative (lipid peroxidation: MDA, SOD and GPx) & Kim et al., 2009 \\
\hline GCl (4VO) & Rat & SD & Ginsenosides Rb + Ro & $\begin{array}{l}\text { - Oxidative stress [Anti-lipid peroxidation: creatine } \\
\text { phosphokinase (CK) and SOD] }\end{array}$ & Chu and Chen, 1990 \\
\hline
\end{tabular}

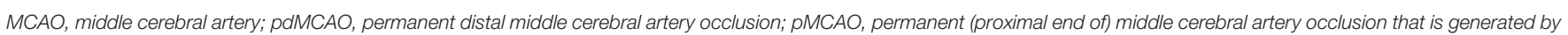
the intraluminal suture MCAO; GCl, global cerebral ischemia; SAH, subarachnoid Hemorrhage; BBB, blood brain barrier; NA, no answer; ND, non-discussed.

inducers, Nrf2 protein is liberated from Kelch-like ECHassociating protein 1 (Keap1)-mediated repression, translocates into the nucleus, binds to the ARE sequence in the promoter region of Nrf2 target proteins, thereby activating a wide range of cytoprotective genes (Hayes and Dinkova-Kostova, 2014). Very recently, pretreatment with KRG, as an Nrf2 inducer, significantly increased the expression levels of Nrf2 target cytoprotective and antioxidant proteins after pdMCAO, which was abolished in ischemic-Nrf2 $2^{-/}$mice, supporting the Nrf2-dependent neuroprotection of KRG in ischemic stroke (Liu et al., 2018b). This is supported by other in vivo (Yang et al., 2015b; Gao et al., 2017a; Li et al., 2017a) and in vitro (Hwang and Jeong, 2010) reports. In addition, pretreatment of ginsenoside $\mathrm{Rb} 1$ was reported to have antioxidant neuroprotective effects through promoting ERK1/2 pathways in cerebral ischemia-induced injuries in aged mice (Dong et al., 2017).

Astrocytes are recognized to exert essential and complex functions for maintaining normal neural activity in the healthy CNS and respond to various forms of CNS injury or disease. Reactive astrogliosis, regulated in a context specific manner, alters astrocytic functions and thereby exerts beneficial effects on neural functions. Given the important role of astrocytes in oxidative stress and inflammation process (Hamby and Sofroniew, 2010; Sofroniew, 2014; Ong et al., 2015), reactive astrogliosis was considered to contribute to the neuroprotection of ginseng in stroke. Indeed, in permanent cerebral ischemia model mice, ginseng pretreatment robustly attenuated the acute reactive astrogliosis progression but not the microglia activation in the ischemic cortex region in an Nrf2-dependent manner. The spatial and temporal pattern correlated well with the acute ischemic damage expansion during the acute stage of ischemia (Liu et al., 2018 b). In addition, ginseng pretreatment was found to attenuate the deterioration of glutamine synthetase, the key enzyme for glutamate metabolism, and aquaporin 4 (AQP4), the unique water channel that is predominantly distributed in astrocytes. One of the major causes of morbidity and mortality after stroke is brain edema; the influence of ginseng on cellular water penetrability at least partly involves its favorable effects on stroke damage. In agreement with this observation, it was reported that the neuroprotection of Rg1 against ischemic-reperfusion brain injury might be associated with the reduced expression AQP4 level (Zhou et al., 2014).

\section{Anti-inflammation}

Inflammation is another major player that is involved in stroke pathogenesis, which contributes to all the stages of the stroke pathophysiology (Iadecola and Anrather, 2011; Fu et al., 2015; Esenwa and Elkind, 2016; de Oliveira Manoel and Macdonald, 2018; Drieu et al., 2018). The inflammatory responses are typically mediated by proinflammatory prostaglandins, cytokines and chemokines. These components attract immune cells, interact with the adaptive immune system, and evoke the systemic release of acute phase reactants (Esenwa and Elkind, 2016). These pro-inflammation proteins include IL-1 $\beta$, IL-6, tumor necrosis factor $\alpha(\mathrm{TNF} \alpha)$, interferon $\gamma$ (IFN $\gamma)$, complement proteins, C-reactive protein (CRP), etc., which are implicated in the pathogenesis and progression of atherosclerosis and intravascular thrombosis (Sofroniew, 2015; Drieu et al., 2018). Anti-inflammatory mediators include IL-4, IL-10, TGF $\beta$, etc. (Mandolesi et al., 2015; Sofroniew, 2015). Microglial activation plays an important role in inflammation, and activated microglia have both pro- and anti-inflammatory properties (Hoogland et al., 2015).

Anti-inflammation might be another intriguing neuroprotective effect of ginseng. Suppression of inflammation contributed to the neuroprotection of $\mathrm{Rb} 1$ on cerebral ischemic injury and the integrity of blood-brain barrier (BBB), indicated by the downregulated expression of pro-inflammatory factors nitric oxide synthase, IL-1 $\beta$, IL- 6 , and upregulated expression of anti-inflammatory markers arginase 1 and IL-10 in the ischemic brain (Zhu et al., 2012; Chen et al., 2015). Rg1 was reported to suppress inflammation and preserve the brain tissue from stroke insults (Wang et al., 2018a), and the underlying mechanism was related to the activation of PPAR $\gamma / \mathrm{HO}-1$ (Yang et al., 2015b) and PPAR $\gamma$-regulated pathways (Li et al., 2017b). The beneficial effect in inhibition of inflammation was also observed in MCAO rats treated with KRG (Ban et al., 2012) or Rd (Zhang et al., 2016). In addition, $\mathrm{Rb} 1$ and $\mathrm{Rd}$ have been shown to repress microglial 
activation and decrease the pro-inflammatory cytokines IL-6 in a transientMCAO rat model, which resulted in a decrease in infarct volume and neurological deficits score (Ye et al., 2011c; Zhu et al., 2012).

Nuclear factor $-\kappa \mathrm{B}(\mathrm{NF}-\kappa \mathrm{B})$ is a critical transcription factor involved in the regulation of inflammation through the target genes such as cycloygenase-2 (COX-2), inducible nitric oxide synthase (iNOS), and IL-6 (Harari and Liao, 2010). A study showed that Rb1 can suppress NF- $\mathrm{B}$ and its DNA binding activity thus suppressing neuronal death as well as decreasing IL-6 levels in the brain with cerebral ischemia (Zhu et al., 2012). Rg1 was shown to exert its neuroprotective action through antioxidative and anti-inflammatory effects mediated by the activation of PPAR $\gamma$ signaling, and the beneficial effect was abolished by a selective PPAR $\gamma$ antagonist GW9662 (Li et al., 2017b). The administration of Rd after stroke inhibited ischemia-induced microglial activation, decreased the expression levels of various proinflammatory cytokines, and suppressed nuclear factor of kappa light polypeptide gene enhancer in

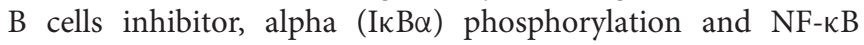
nuclear translocation (Zhang et al., 2016). The anti-inflammatory effect of $\mathrm{Rd}$ was also supported by another report. It was shown that Rd significantly eliminated inflammatory injury as indicated by the suppression of microglial activation and reduced pro-inflammatory factors levels (Ye et al., 2011c). Mitogen-activated protein kinases (MAPKs) mediate another group of signal transduction pathways activated by stress and inflammation that enhance the formation of pro-inflammatory proteins in stroke. The p38 MAPK can downregulate HO1 expression, which has potent anti-inflammatory, antioxidant and anti-apoptotic properties (Naidu et al., 2009; Jang et al., 2012; Wang et al., 2015). Compound $\mathrm{K}$ showed a neuroprotective effect on experimental stroke in mice through inhibiting phosphorylation of MAPKs and enhancing HOl expression, thus decreasing production of pro-inflammatory proteins in activated microglia (Park et al., 2012).

\section{Anti-apoptosis}

Another important role of ginseng on ischemic stroke is the inhibition of apoptosis or cell death. There is a dynamic balance between anti-apoptotic proteins (such as Bcl-2) and proapoptotic proteins [such as $\mathrm{Bcl}-2$-associated $\mathrm{X}$ protein (Bax)], playing a major role in regulating apoptosis. Rb1 was shown to increase $\mathrm{Bcl}-2$ protein and decrease BAX protein in MCAO model rats (Yuan et al., 2007). Similarly, Rg2 was shown to increase $\mathrm{Bcl}-2$ protein and decrease Bax protein in rats after MCAO (Zhang et al., 2008b). Bcl-2 is mainly located in the mitochondrial outer membrane, and cytochrome c, a small heme protein, is mainly located in the mitochondrial inner membrane, signifying the important role of mitochondria in apoptosis process. Rd was reported to attenuate mitochondrial release of AIF, caspase 3 and cytochrome $c$ in MCAO rats, leading to the benefit of $\mathrm{Rd}$ on ischemic brain lesion (Ye et al., 2011d). Rb1 can also decrease the activity of caspase 3 in the ischemic brain of rats, thus inhibiting cell death after MCAO (Gao et al., 2010). KRG extract decreased the number of apoptosis signal-regulating kinase 1 (ASK1)-positive cells and the expression level of ASK1 protein in the ischemic region at 4 and $24 \mathrm{~h}$ after MCAO, resulting a better performance in ischemic rats (Cheon et al., 2013).

\section{Anti-autophagy}

Autophagy is a self-eating cellular catabolic pathway, degrading and recycling damaged organelles and misfolded proteins for cellular homeostasis (Wang et al., 2018b). Due to its important homeostatic role in regulating cell survival, emerging evidence showed that autophagy is implicated in the destructive process in stroke (Wu et al., 2016; Li et al., 2018a). LC3, a crucial protein for autophagy, is mainly located in the cytoplasm and concentrated in autophagosomes during autophagy. Beclin1 also plays a key role in the regulation of autophagosome formation. In MCAO model rats, Rb1 attenuated autophagy via a decrease in the associated proteins LC3 and Beclin 1 in transient MCAO rat models (Lu et al., 2011). In GCI (2VO) model rats, Rb1 administration inhibited autophagy in hippocampal CA1 neurons, evidenced by the expression level of autophagy hallmark proteins LC3 (I and II) and Beclin1 in CA1 neurons by confocal microscopy and Western blot (Luo et al., 2014).

\section{Other Beneficial Mechanisms}

Stroke is a heterogeneous and multi-factorial cerebrovascular disease; multiple cell death pathways are evoked in response to acute brain injury (Kellner and Connolly, 2010; Fisher, 2011; Tasker and Duncan, 2015). Such injury induces various endogenous protective mechanisms, including neurogenesis, angiogenesis, and vascular remodeling responses (Marti and Risau, 1999; Greenberg, 2014; Seto et al., 2016; Koh and Park, 2017). To enhance the endogenous neurogenesis driven by ischemia and promote the survival of newborn neurons are considered as the promising therapeutic interventions for stroke (Lu et al., 2017). It was shown that GST and Rb1 increased the numbers of neuronal precursors and promoted the proliferation of endogenous neural stem cells, thus promoting the behavior recovery post-ischemia (Gao et al., 2010; Zheng et al., 2011). Re was shown to improve the fluidity of the mitochondrial membrane that was important for energy generation (Zhou et al., 2006).

Angiogenesis refers to the process of new blood vessel formation from the existing vasculature (Adair and Montani, 2010). Although the vascular system in the adult brain is extremely stable under normal conditions, pathological angiogenesis is induced in response to brain ischemia. The angiogenesis induction, mainly in the ischemic area, enhances the supply of oxygen and nutrients. Therefore, post-stroke angiogenesis facilitates the process of vascular remodeling and is considered a harmonized target for neurological recovery (Mennel, 2000; Beck and Plate, 2009; Dejana, 2010; Xiong et al., 2010; Ergul et al., 2012). The angiogenic factors are induced within hours following stroke, and new capillaries are developed within days (Greenberg, 2014). Ginsengosides have indicated salutary effects on angiogenesis in stroke through inducing various angiogenesis regulators. Ginsenoside $\operatorname{Rg} 1$ was shown to facilitate angiogenesis after hypoxia/ischemia brain injury, and the pharmacological effects of $\operatorname{Rg} 1$ may be attributed to the 
regulation of the vascular endothelial growth factor (VEGF) and cleaved caspase 3 expression levels (Tang et al., 2017). Ginsenoside Rg1 was also reported to improve angiogenesis in the diabetic ischemic hind limb, and the potential mechanism might be related to the eNOS activation and upregulation of the VEGF expression (Yang et al., 2012).

\section{TRANSLATIONAL POTENTIAL OF GINSENG AND GINSENOSIDES IN STROKE THERAPEUTICS}

Since 1996 till now, one strategy for improving functional recovery after ischemic stroke is to restore blood flow to salvage ischemic tissue by introducing intravenous recombinant tissue plasminogen activator (rtPA) in acute ischemic stroke, while the other protocol if removal of the blood clot by thrombectomy (Prabhakaran et al., 2015; Romano and Sacco, 2015). Despite that only $<40 \%$ patients who are treated with rtPA alone regain functional independence (Saver et al., 2015), more than 95\% of patients receive only supportive care without rtPA treatment due to the narrow therapeutic window (up to $4.5 \mathrm{~h}$ ) and limited indications (Hacke et al., 2008; Fonarow et al., 2011; Sandercock et al., 2012; Emberson et al., 2014). The other strategy is neuroprotection targeting various components of the cascade during ischemic insult, which is supported by preclinical data for many agents (Fisher, 2011; Dirnagl and Endres, 2014; Fisher and Saver, 2015). Unfortunately, all prior drug development of neuroprotective agents has been unsuccessful, no neuroprotective drug demonstrated unequivocal efficacy in clinical trials (Fisher, 2006; Hossmann, 2006; Della-Morte et al., 2013).

Many single-target stroke intervention strategies have failed to provide efficacy in clinical trials. The field is in tremendous need of new targets that exert pleiotropic effects on cellular viability through multiple mechanisms. Interestingly, ginseng could be beneficial for the prevention or treatment of stroke through regulating multipronged mechanisms that can provide the brain/cells with resistance against acute and chronic debilitating neurodegenerative conditions. Living organisms are continuously threatened by the damage caused by free radicals produced during normal oxygen metabolism and mitochondrial function or generated by exogenous damage. For centuries, ginseng has been reported as a preventive medicine capable of boosting the nervous system, but the effects on stroke and the underlying cellular mechanisms are still unclear. Increasing in vivo pre-clinical stroke studies of either pretreatment or posttreatment will provide a better understanding of the unique properties of ginseng and its derivatives in the preventive and therapeutic treatment of stroke.

\section{CONCLUDING REMARKS}

The promising preventive and therapeutic efficacy of ginseng or ginsenosides on experimental stroke damage has been illuminated during the last decade. The putative neuroprotective mechanisms of ginseng or ginsenosides include antioxidant, anti-inflammation, anti-apoptosis, anti-autophagy, neurogenesis, and others. These effects have the potential to influence short- and long-term complex neurobehaviors such as the overall deficits, motor, sensorimotor, and cognition. It is known that stroke injury results in severe motor, sensory, emotional, and cognitive deficits (Ferro et al., 2016), and long-term functional recovery is considered as the ultimate goal of stroke intervention. Accordingly, more effective and long-term histological and neurological assessments are expected for future preclinical stroke studies. In addition, the responses to various forms of stroke insults involve complicated interactions among brain cells with numerous functions and lineages, including intrinsic neural cells, intrinsic non-neural cells, and extrinsic cells that come from the circulation. The contributions of different non-neuronal cell types to the progress after acute brain injury are of robust interests for future studies as the impetus toward understanding and ameliorating stroke insults.

\section{REVIEW CRITERIA}

We searched the PubMed and Embase databases by Jan 31, 2019 for the following terms individually or in combination: "ginseng," "ginsenoside," "stroke," "ischemi*” "ischaemi*”" "hemorrhage," "hemorrhagic," "subarachnoid," "mouse," "rat," and their abbreviations. Study selection for inclusion and exclusion was performed based on predefined criteria. Selection of articles: (1) The studies were published in English; (2) The study clearly described the stroke model and administration route of ginseng or ginsenosides; (3) Ginseng or ginsenosides were administrated without the combination of other compounds. (4) The study was an original full paper that presented the data. Totally 402 articles in PubMed and 454 articles in Embase were identified. After screening analysis in title, abstract and full text and duplication analysis, 54 articles met inclusion criteria. Three independent investigators reviewed articles and extracted data for study design elements, such as animals, animal models, administration strategies, stroke outcomes, and mechanisms. We specifically focus on the in vivo evidence for the effects of ginseng and ginsenosides on various stroke damages and mechanism.

\section{AUTHOR CONTRIBUTIONS}

LL and SD conceived the study, designed the databases analysis, and wrote the manuscript. LL, GA, and TF searched databases, collected data, performed analyses, and prepared the tables and figure. All authors discussed and approved the final manuscript.

\section{ACKNOWLEDGMENTS}

This review was supported in part by National Institutes of Health grants R01AT007429 and R01NS046400 (SD) and the American Heart Association Postdoctoral Fellowship 16POST31220032 (LL). 


\section{REFERENCES}

Adair, T. H., and Montani, J. P. (2010). Angiogenesis. San Rafael, CA: Morgan \& Claypool Life Sciences.

Ahmad, A. S., Mendes, M., Hernandez, D., and Doré, S. (2017). Efficacy of laropiprant in minimizing brain injury following experimental intracerebral hemorrhage. Sci. Rep. 7:9489. doi: 10.1038/s41598-017-09994-5

Ahmed, T., Raza, S. H., Maryam, A., Setzer, W. N., Braidy, N., Nabavi, S. F., et al. (2016). Ginsenoside Rb1 as a neuroprotective agent: a review. Brain Res. Bull. 125, 30-43. doi: 10.1016/j.brainresbull.2016.04.002

An, X., Zhang, A. L., Yang, A. W., Lin, L., Wu, D., Guo, X., et al. (2011). Oral ginseng formulae for stable chronic obstructive pulmonary disease: a systematic review. Respir. Med. 105, 165-176. doi: 10.1016/j.rmed.2010.11.007

Annunziato, L., Boscia, F., and Pignataro, G. (2013). Ionic transporter activity in astrocytes, microglia, and oligodendrocytes during brain ischemia. J. Cereb. Blood Flow Metab. 33, 969-982. doi: 10.1038/jcbfm.2013.44

Arring, N. M., Millstine, D., Marks, L. A., and Nail, L. M. (2018). Ginseng as a treatment for fatigue: a systematic review. J. Altern. Complement. Med. 24, 624-633. doi: $10.1089 / \mathrm{acm} .2017 .0361$

Bae, E. A., Hyun, Y. J., Choo, M. K., Oh, J. K., Ryu, J. H., and Kim, D. H. (2004). Protective effect of fermented red ginseng on a transient focal ischemic rats. Arch. Pharm. Res. 27, 1136-1140. doi: 10.1007/BF02975119

Baek, S. H., Bae, O. N., and Park, J. H. (2012). Recent methodology in ginseng analysis. J. Ginseng. Res. 36, 119-134. doi: 10.5142/jgr.2012.36.2.119

Balaban, R. S., Nemoto, S., and Finkel, T. (2005). Mitochondria, oxidants, and aging. Cell 120, 483-495. doi: 10.1016/j.cell.2005.02.001

Ban, J. Y., Kang, S. W., Lee, J. S., Chung, J. H., Ko, Y. G., and Choi, H. S. (2012). Korean red ginseng protects against neuronal damage induced by transient focal ischemia in rats. Exp. Ther. Med. 3, 693-698. doi: 10.3892/etm.2012.449

Becerra-Calixto, A., and Cardona-Gomez, G. P. (2017). The role of astrocytes in neuroprotection after brain stroke: potential in cell therapy. Front. Mol. Neurosci. 10:88. doi: 10.3389/fnmol.2017.00088

Beck, H., and Plate, K. H. (2009). Angiogenesis after cerebral ischemia. Acta Neuropathol. 117, 481-496. doi: 10.1007/s00401-009-0483-6

Benjamin, E. J., Virani, S. S., Callaway, C. W., Chamberlain, A. M., Chang, A. R., Cheng, S., et al. (2018). Heart disease and stroke statistics-2018 update: a report from the American Heart Association. Circulation 137, e67-e492. doi: 10.1161/CIR.0000000000000558

Bernhardt, J., Zorowitz, R. D., Becker, K. J., Keller, E., Saposnik, G., Strbian, D., et al. (2018). Advances in stroke 2017. Stroke 49, e174-e199. doi: 10.1161/STROKEAHA.118.021380

Bhatti, J. S., Bhatti, G. K., and Reddy, P. H. (2017). Mitochondrial dysfunction and oxidative stress in metabolic disorders - a step towards mitochondria based therapeutic strategies. Biochim. Biophys. Acta 1863, 1066-1077. doi: 10.1016/j.bbadis.2016.11.010

Bjorklund, G., Dadar, M., Martins, N., Chirumbolo, S., Goh, B. H., Smetanina, K., et al. (2018). Brief challenges on medicinal plants: an eye-opening look at ageing-related disorders. Basic Clin. Pharmacol. Toxicol. 122, 539-558. doi: $10.1111 /$ bcpt.12972

Carbone, F., Teixeira, P. C., Braunersreuther, V., Mach, F., Vuilleumier, N., and Montecucco, F. (2015). Pathophysiology and treatments of oxidative injury in ischemic stroke: focus on the phagocytic NADPH oxidase 2. Antioxid. Redox Signal. 23, 460-489. doi: 10.1089/ars.2013.5778

Chen, G., Yang, M., Song, Y., Lu, Z., Zhang, J., Huang, H., et al. (2008a). Comparative analysis on microbial and rat metabolism of ginsenoside $\mathrm{Rb} 1$ by high-performance liquid chromatography coupled with tandem mass spectrometry. Biomed. Chromatogr. 22, 779-785. doi: 10.1002/bmc.1001

Chen, H., Yoshioka, H., Kim, G. S., Jung, J. E., Okami, N., Sakata, H., et al. (2011). Oxidative stress in ischemic brain damage: mechanisms of cell death and potential molecular targets for neuroprotection. Antioxid. Redox Signal. 14, 1505-1517. doi: 10.1089/ars.2010.3576

Chen, L. M., Zhou, X. M., Cao, Y. L., and Hu, W. X. (2008b). Neuroprotection of ginsenoside Re in cerebral ischemia-reperfusion injury in rats. J. Asian Nat. Prod. Res. 10, 439-445. doi: 10.1080/10286020801892292

Chen, W., Guo, Y., Yang, W., Zheng, P., Zeng, J., and Tong, W. (2015). Protective effect of ginsenoside Rb1 on integrity of blood-brain barrier following cerebral ischemia. Exp. Brain. Res. 233, 2823-2831. doi: 10.1007/s00221-015-4352-3
Cheon, S. Y., Cho, K. J., Lee, J. E., Kim, H. W., Lee, S. K., Kim, H. J., et al. (2013). Cerebroprotective effects of red ginseng extract pretreatment against ischemia-induced oxidative stress and apoptosis. Int. J. Neurosci. 123, 269-277. doi: 10.3109/00207454.2012.758120

Choi, S. R., Saji, H., Iida, Y., Magata, Y., and Yokoyama, A. (1996). Ginseng pretreatment protects against transient global cerebral ischemia in the rat: measurement of local cerebral glucose utilization by [14C]deoxyglucose autoradiography. Biol. Pharm. Bull. 19, 644-646. doi: 10.1248/bpb.19.644

Christensen, L. P. (2009). Ginsenosides chemistry, biosynthesis, analysis, and potential health effects. Adv. Food Nutr. Res. 55, 1-99. doi: 10.1016/S1043-4526(08)00401-4

Chu, G. X., and Chen, X. (1990). Anti-lipid peroxidation and protection of ginsenosides against cerebral ischemia-reperfusion injuries in rats. Zhongguo Yao Li Xue Bao 11, 119-123.

Colzani, M., Altomare, A., Caliendo, M., Aldini, G., Righetti, P. G., and Fasoli, E. (2016). The secrets of Oriental panacea: Panax ginseng. J. Proteomics 130, 150-159. doi: 10.1016/j.jprot.2015.09.023

Cuadrado, A., Manda, G., Hassan, A., Alcaraz, M. J., Barbas, C., Daiber, A., et al. (2018). Transcription factor NRF2 as a therapeutic target for chronic diseases: a systems medicine approach. Pharmacol. Rev. 70, 348-383. doi: $10.1124 /$ pr.117.014753

de Oliveira Manoel, A. L., and Macdonald, R. L. (2018). Neuroinflammation as a target for intervention in subarachnoid hemorrhage. Front. Neurol. 9:292. doi: $10.3389 /$ fneur.2018.00292

Dejana, E. (2010). The role of wnt signaling in physiological and pathological angiogenesis. Circ. Res. 107, 943-952. doi: 10.1161/CIRCRESAHA.110.223750

Della-Morte, D., Cacciatore, F., Salsano, E., Pirozzi, G., Del Genio, M. T., D’antonio I, et al. (2013). Age-related reduction of cerebral ischemic preconditioning: myth or reality? Clin. Interv. Aging 8, 1055-1061. doi: 10.2147/CIA.S47462

Dirnagl, U., and Endres, M. (2014). Found in translation: preclinical stroke research predicts human pathophysiology, clinical phenotypes, and therapeutic outcomes. Stroke 45, 1510-1518. doi: 10.1161/STROKEAHA.113.004075

Dong, X., Zheng, L., Lu, S., and Yang, Y. (2017). Neuroprotective effects of pretreatment of ginsenoside $\mathrm{Rb} 1$ on severe cerebral ischemia-induced injuries in aged mice: involvement of anti-oxidant signaling. Geriatr. Gerontol. Int. 17, 338-345. doi: 10.1111/ggi.12699

Dorr, A., Sled, J. G., and Kabani, N. (2007). Three-dimensional cerebral vasculature of the CBA mouse brain: a magnetic resonance imaging and micro computed tomography study. Neuroimage 35, 1409-1423. doi: 10.1016/j.neuroimage.2006.12.040

Doyle, K. P., and Buckwalter, M. S. (2014). A mouse model of permanent focal ischemia: distal middle cerebral artery occlusion. Methods Mol Biol 1135, 103-110. doi: 10.1007/978-1-4939-0320-7 9

Drieu, A., Levard, D., Vivien, D., and Rubio, M. (2018). Anti-inflammatory treatments for stroke: from bench to bedside. Ther. Adv. Neurol. Disord. 11:1756286418789854. doi: 10.1177/1756286418789854

Drummond, G. R., Selemidis, S., Griendling, K. K., and Sobey, C. G. (2011). Combating oxidative stress in vascular disease: NADPH oxidases as therapeutic targets. Nat. Rev. Drug Discov. 10, 453-471. doi: 10.1038/nrd3403

Emberson, J., Lees, K. R., Lyden, P., Blackwell, L., Albers, G., Bluhmki, E., et al. (2014). Effect of treatment delay, age, and stroke severity on the effects of intravenous thrombolysis with alteplase for acute ischaemic stroke: a meta-analysis of individual patient data from randomised trials. Lancet 384, 1929-1935. doi: 10.1016/S0140-6736(14)60584-5

Ergul, A., Alhusban, A., and Fagan, S. C. (2012). Angiogenesis: a harmonized target for recovery after stroke. Stroke 43, 2270-2274. doi: 10.1161/STROKEAHA.111.642710

Esenwa, C. C., and Elkind, M. S. (2016). Inflammatory risk factors, biomarkers and associated therapy in ischaemic stroke. Nat. Rev. Neurol. 12, 594-604. doi: 10.1038/nrneurol.2016.125

Feigin, V. L., Norrving, B., George, M. G., Foltz, J. L., Roth, G. A., and Mensah, G. A. (2016). Prevention of stroke: a strategic global imperative. Nat. Rev. Neurol. 12, 501-512. doi: 10.1038/nrneurol.2016.107

Feigin, V. L., Norrving, B., and Mensah, G. A. (2017). Global Burden of Stroke. Circ. Res. 120, 439-448. doi: 10.1161/CIRCRESAHA.116.308413

Ferro, J. M., Caeiro, L., and Figueira, M. L. (2016). Neuropsychiatric sequelae of stroke. Nat. Rev. Neurol. 12, 269-280. doi: 10.1038/nrneurol.2016.46 
Fisher, M. (2006). The ischemic penumbra: a new opportunity for neuroprotection. Cerebrovasc. Dis. 21(Suppl. 2), 64-70. doi: 10.1159/000091705

Fisher, M. (2011). New approaches to neuroprotective drug development. Stroke 42, S24-27. doi: 10.1161/STROKEAHA.110.592394

Fisher, M., and Saver, J. L. (2015). Future directions of acute ischaemic stroke therapy. Lancet Neurol. 14, 758-767. doi: 10.1016/S1474-4422(15)00054-X

Flynn, J. M., and Melov, S. (2013). SOD2 in mitochondrial dysfunction and neurodegeneration. Free Radic. Biol. Med. 62, 4-12. doi: 10.1016/j.freeradbiomed.2013.05.027

Fonarow, G. C., Smith, E. E., Saver, J. L., Reeves, M. J., Bhatt, D. L., GrauSepulveda, M. V., et al. (2011). Timeliness of tissue-type plasminogen activator therapy in acute ischemic stroke: patient characteristics, hospital factors, and outcomes associated with door-to-needle times within 60 minutes. Circulation 123, 750-758. doi: 10.1161/CIRCULATIONAHA.110.974675

Fu, Y., Liu, Q., Anrather, J., and Shi, F. D. (2015). Immune interventions in stroke. Nat. Rev. Neurol. 11, 524-535. doi: 10.1038/nrneurol.2015.144

Gan, X. T., and Karmazyn, M. (2018). Cardioprotection by ginseng: experimental and clinical evidence and underlying mechanisms. Can. J. Physiol. Pharmacol. 96, 859-868. doi: 10.1139/cjpp-2018-0192

Gao, X. Q., Yang, C. X., Chen, G. J., Wang, G. Y., Chen, B., Tan, S. K., et al. (2010). Ginsenoside Rb1 regulates the expressions of brain-derived neurotrophic factor and caspase- 3 and induces neurogenesis in rats with experimental cerebral ischemia. J. Ethnopharmacol. 132, 393-399. doi: 10.1016/j.jep.2010.07.033

Gao, Y., Chu, S., Shao, Q., Zhang, M., Xia, C., Wang, Y., et al. (2017a). Antioxidant activities of ginsenoside Rg1 against cisplatin-induced hepatic injury through Nrf2 signaling pathway in mice. Free Radic. Res. 51, 1-13. doi: $10.1080 / 10715762.2016 .1234710$

Gao, Y., Chu, S., Zhang, Z., and Chen, N. (2017b). Hepataprotective effects of ginsenoside Rg1 - a review. J. Ethnopharmacol. 206, 178-183. doi: 10.1016/j.jep.2017.04.012

Ghosh, N., Ghosh, R., and Mandal, S. C. (2011). Antioxidant protection: a promising therapeutic intervention in neurodegenerative disease. Free Radic. Res. 45, 888-905. doi: 10.3109/10715762.2011.574290

Gonzalez-Burgos, E., Fernandez-Moriano, C., and Gomez-Serranillos, M. P. (2015). Potential neuroprotective activity of Ginseng in Parkinson's disease: a review. J. Neuroimmun. Pharmacol. 10, 14-29. doi: 10.1007/s11481-014-9569-6

Greenberg, D. A. (2014). Cerebral angiogenesis: a realistic therapy for ischemic disease? Methods Mol. Biol. 1135, 21-24. doi: 10.1007/978-1-4939-0320-7_2

Hacke, W., Kaste, M., Bluhmki, E., Brozman, M., Davalos, A., Guidetti, D., et al. (2008). Thrombolysis with alteplase 3 to 4.5 hours after acute ischemic stroke. N. Engl. J. Med. 359, 1317-1329. doi: 10.1056/NEJMoa0804656

Hamby, M. E., and Sofroniew, M. V. (2010). Reactive astrocytes as therapeutic targets for CNS disorders. Neurotherapentics 7, 494-506. doi: 10.1016/j.nurt.2010.07.003

Harari, O. A., and Liao, J. K. (2010). NF-kappaB and innate immunity in ischemic stroke. Ann. N. Y. Acad. Sci. 1207, 32-40. doi: 10.1111/j.1749-6632.2010.05735.x

Hayes, J. D., and Dinkova-Kostova, A. T. (2014). The Nrf2 regulatory network provides an interface between redox and intermediary metabolism. Trends Biochem. Sci. 39, 199-218. doi: 10.1016/j.tibs.2014.02.002

He, B., Chen, P., Yang, J., Yun, Y., Zhang, X., Yang, R., et al. (2012). Neuroprotective effect of 20(R)-ginsenoside $\operatorname{Rg}(3)$ against transient focal cerebral ischemia in rats. Neurosci. Lett. 526, 106-111. doi: 10.1016/j.neulet.2012.08.022

He, M., Huang, X., Liu, S., Guo, C., Xie, Y., Meijer, A. H., et al. (2018). The difference between white and red ginseng: variations in ginsenosides and immunomodulation. Planta. Med. 84, 845-854. doi: 10.1055/a-0641-6240

Hoogland, I. C., Houbolt, C., Van Westerloo, D. J., Van Gool, W. A., and Van De Beek, D. (2015). Systemic inflammation and microglial activation: systematic review of animal experiments. J. Neuroinflammation 12:114. doi: 10.1186/s12974-015-0332-6

Hossmann, K. A. (2006). Pathophysiology and therapy of experimental stroke. Cell Mol. Neurobiol. 26, 1057-1083. doi: 10.1007/s10571-006-9008-1

Hu, G., Wu, Z., Yang, F., Zhao, H., Liu, X., Deng, Y., et al. (2013). Ginsenoside Rd blocks AIF mitochondrio-nuclear translocation and NF-kappaB nuclear accumulation by inhibiting poly(ADP-ribose) polymerase- 1 after focal cerebral ischemia in rats. Neurol. Sci. 34, 2101-2106. doi: 10.1007/s10072-013-1344-6

Hwang, Y. P., and Jeong, H. G. (2010). Ginsenoside Rb1 protects against 6hydroxydopamine-induced oxidative stress by increasing heme oxygenase-1 expression through an estrogen receptor-related PI3K/Akt/Nrf2-dependent pathway in human dopaminergic cells. Toxicol. Appl. Pharmacol. 242, 18-28. doi: 10.1016/j.taap.2009.09.009

Iadecola, C., and Anrather, J. (2011). The immunology of stroke: from mechanisms to translation. Nat. Med. 17, 796-808. doi: 10.1038/nm.2399

Im, D. S., and Nah, S. Y. (2013). Yin and Yang of ginseng pharmacology: ginsenosides vs gintonin. Acta Pharmacol. Sin. 34, 1367-1373. doi: 10.1038/aps.2013.100

Jang, H. J., Kim, Y. M., Tsoyi, K., Park, E. J., Lee, Y. S., Kim, H. J., et al. (2012). Ethyl pyruvate induces heme oxygenase-1 through p38 mitogen-activated protein kinase activation by depletion of glutathione in RAW 264.7 cells and improves survival in septic animals. Antioxid. Redox Signal. 17, 878-889. doi: 10.1089/ars.2011.3994

Jin, Y., Kim, Y. J., Jeon, J. N., Wang, C., Min, J. W., Noh, H. Y., et al. (2015). Effect of white, red and black ginseng on physicochemical properties and ginsenosides. Plant Foods Hum. Nutr. 70, 141-145. doi: 10.1007/s11130-015-0470-0

Karmazyn, M., Moey, M., and Gan, X. T. (2011). Therapeutic potential of ginseng in the management of cardiovascular disorders. Drugs 71, 1989-2008. doi: 10.2165/11594300-000000000-00000

Kellner, C. P., and Connolly, E. S. Jr. (2010). Neuroprotective strategies for intracerebral hemorrhage: trials and translation. Stroke 41, S99-102. doi: 10.1161/STROKEAHA.110.597476

Kim, J. H. (2018). Pharmacological and medical applications of Panax ginseng and ginsenosides: a review for use in cardiovascular diseases. J. Ginseng. Res. 42, 264-269. doi: 10.1016/j.jgr.2017.10.004

Kim, K. H., Lee, D., Lee, H. L., Kim, C. E., Jung, K., and Kang, K. S. (2018). Beneficial effects of Panax ginseng for the treatment and prevention of neurodegenerative diseases: past findings and future directions. J. Ginseng. Res. 42, 239-247. doi: 10.1016/j.jgr.2017.03.011

Kim, Y. O., Kim, H. J., Kim, G. S., Park, H. G., Lim, S. J., Seong, N. S., et al. (2009). Panax ginseng protects against global ischemia injury in rat hippocampus. $J$. Med. Food 12, 71-76. doi: 10.1089/jmf.2007.0614

Koh, S. H., and Park, H. H. (2017). Neurogenesis in stroke recovery. Transl. Stroke Res. 8, 3-13. doi: 10.1007/s12975-016-0460-z

Leclerc, J. L., Garcia, J. M., Diller, M. A., Carpenter, A. M., Kamat, P. K., Hoh, B. L., et al. (2018). A comparison of pathophysiology in humans and rodent models of subarachnoid hemorrhage. Front. Mol. Neurosci. 11:71. doi: 10.3389/fnmol.2018.00071

Lee, J. S., Choi, H. S., Kang, S. W., Chung, J. H., Park, H. K., Ban, J. Y., et al. (2011). Therapeutic effect of Korean red ginseng on inflammatory cytokines in rats with focal cerebral ischemia/reperfusion injury. Am. J. Chin. Med. 39, 83-94. doi: 10.1142/S0192415X1100866X

Lee, M. S., Yang, E. J., Kim, J. I., and Ernst, E. (2009). Ginseng for cognitive function in Alzheimer's disease: a systematic review. J. Alzheimers Dis. 18, 339-344. doi: 10.3233/JAD-2009-1149

Lee, S. M., Bae, B. S., Park, H. W., Ahn, N. G., Cho, B. G., Cho, Y. L., et al. (2015). Characterization of Korean Red Ginseng (Panax ginseng Meyer): history, preparation method, and chemical composition. J. Ginseng. Res. 39, 384-391. doi: 10.1016/j.jgr.2015.04.009

Lee, Y. M., Yoon, H., Park, H. M., Song, B. C., and Yeum, K. J. (2017). Implications of red Panax ginseng in oxidative stress associated chronic diseases. J. Ginseng. Res. 41, 113-119. doi: 10.1016/j.jgr.2016.03.003

Li, H., Wu, J., Shen, H., Yao, X., Liu, C., Pianta, S., et al. (2018a). Autophagy in hemorrhagic stroke: Mechanisms and clinical implications. Prog. Neurobiol. 163-164, 79-97. doi: 10.1016/j.pneurobio.2017.04.002

Li, P., Hu, X., Gan, Y., Gao, Y., Liang, W., and Chen, J. (2011a). Mechanistic insight into DNA damage and repair in ischemic stroke: exploiting the base excision repair pathway as a model of neuroprotection. Antioxid. Redox Signal. 14, 1905-1918. doi: 10.1089/ars.2010.3451

Li, Q., Xiang, Y., Chen, Y., Tang, Y., and Zhang, Y. (2017a). Ginsenoside Rg1 protects cardiomyocytes against hypoxia/reoxygenation injury via activation of Nrf2/HO-1 signaling and inhibition of JNK. Cell Physiol. Biochem. 44, 21-37. doi: $10.1159 / 000484578$

Li, Y., Guan, Y., Wang, Y., Yu, C. L., Zhai, F. G., and Guan, L. X. (2017b). Neuroprotective effect of the Ginsenoside Rg1 on cerebral ischemic injury in vivo and in vitro is mediated by PPARgamma-regulated antioxidative and antiinflammatory pathways. Evid. Based Complement Alternat. Med. 2017:7842082. doi: $10.1155 / 2017 / 7842082$ 
Li, Y., Tang, J., Khatibi, N. H., Zhu, M., Chen, D., Tu, L., et al. (2011b). Treatment with ginsenoside Rb1, a component of panax ginseng, provides neuroprotection in rats subjected to subarachnoid hemorrhage-induced brain injury. Acta Neurochir. Suppl. 110, 75-79. doi: 10.1007/978-3-7091-0356-2_14

Li, Y., Tang, J., Khatibi, N. H., Zhu, M., Chen, D., Zheng, W., et al. (2010). Ginsenoside Rbetal reduces neurologic damage, is anti-apoptotic, and downregulates p53 and BAX in subarachnoid hemorrhage. Curr. Neurovasc. Res. 7, 85-94. doi: 10.2174/156720210791184952

Li, Y., Xu, Q. Q., Shan, C. S., Shi, Y. H., Wang, Y., and Zheng, G. Q. (2018b). Combined use of emodin and ginsenoside Rbl Exerts synergistic neuroprotection in cerebral ischemia/reperfusion rats. Front. Pharmacol. 9:943. doi: 10.3389/fphar.2018.00943

Lin, M., Sun, W., Gong, W., Ding, Y., Zhuang, Y., and Hou, Q. (2015). Ginsenoside Rg1 protects against transient focal cerebral ischemic injury and suppresses its systemic metabolic changes in cerabral injury rats. Acta Pharm. Sin. B 5, 277-284. doi: 10.1016/j.apsb.2015.02.001

Lin, M. T., and Beal, M. F. (2006). Mitochondrial dysfunction and oxidative stress in neurodegenerative diseases. Nature 443, 787-795. doi: 10.1038/nature05292

Liu, A., Zhu, W., Sun, L., Han, G., Liu, H., Chen, Z., et al. (2018a). Ginsenoside $\mathrm{Rb} 1$ administration attenuates focal cerebral ischemic reperfusion injury through inhibition of HMGB1 and inflammation signals. Exp. Ther. Med. 16, 3020-3026. doi: 10.3892/etm.2018.6523

Liu, J. W., Ren, Y. L., Liu, X. L., Xia, H. L., Zhang, H. L., Jin, S. H., et al. (2013). [Effect of ginsenoside Rb1 on cerebral infarction volume and IL-1 beta in the brain tissue and sera of focal cerebral ischemia/reperfusion injury model rats]. Zhongguo Zhong Xi Yi Jie He Za Zhi 33, 1696-1700.

Liu, L., Vollmer, M. K., Ahmad, A. S., Fernandez, V. M., Kim, H., and Dore, S. (2019). Pretreatment with Korean red ginseng or dimethyl fumarate attenuates reactive gliosis and confers sustained neuroprotection against cerebral hypoxicischemic damage by an Nrf2-dependent mechanism. Free Radic. Biol. Med. 131, 98-114. doi: 10.1016/j.freeradbiomed.2018.11.017

Liu, L., Vollmer, M. K., Fernandez, V. M., Dweik, Y., Kim, H., and Doré, S. (2018b). Korean red ginseng pretreatment protects against long-term sensorimotor deficits after ischemic stroke likely through Nrf2. Front. Cell Neurosci. 12:74. doi: 10.3389/fncel.2018.00074

Liu, L., Zhu, X. M., Wang, Q. J., Zhang, D. L., Fang, Z. M., Wang, C. Y., et al. (2010). Enzymatic preparation of 20(S, R)-protopanaxadiol by transformation of 20(S, R)-Rg3 from black ginseng. Phytochemistry 71, 1514-1520. doi: 10.1016/j.phytochem.2010.05.007

Liu, X. Y., Zhou, X. Y., Hou, J. C., Zhu, H., Wang, Z., Liu, J. X., et al. (2015), Ginsenoside Rd promotes neurogenesis in rat brain after transient focal cerebral ischemia via activation of PI3K/Akt pathway. Acta Pharmacol. Sin. 36, 421-428. doi: 10.1038/aps.2014.156

Lo, E. H., Dalkara, T., and Moskowitz, M. A. (2003). Mechanisms, challenges and opportunities in stroke. Nat. Rev. Neurosci. 4, 399-415. doi: 10.1038/nrn1106

Lu, J., Manaenko, A., and Hu, Q. (2017). Targeting adult neurogenesis for poststroke therapy. Stem Cells Int. 2017:5868632. doi: 10.1155/2017/5868632

Lu, T., Jiang, Y., Zhou, Z., Yue, X., Wei, N., Chen, Z., et al. (2011). Intranasal ginsenoside $\mathrm{Rb} 1$ targets the brain and ameliorates cerebral ischemia/reperfusion injury in rats. Biol. Pharm. Bull. 34, 1319-1324. doi: 10.1248/bpb.34.1319

Luo, T., Liu, G., Ma, H., Lu, B., Xu, H., Wang, Y., et al. (2014). Inhibition of autophagy via activation of PI3K/Akt pathway contributes to the protection of ginsenoside Rb1 against neuronal death caused by ischemic insults. Int. J. Mol. Sci. 15, 15426-15442. doi: 10.3390/ijms150915426

Ma, B., Day, J. P., Phillips, H., Slootsky, B., Tolosano, E., and Doré, S. (2016). Deletion of the hemopexin or heme oxygenase- 2 gene aggravates brain injury following stroma-free hemoglobin-induced intracerebral hemorrhage. J. Neuroinflammation 13:26. doi: 10.1186/s12974-016-0490-1

Ma, Q. (2013). Role of nrf2 in oxidative stress and toxicity. Annu. Rev. Pharmacol. Toxicol. 53, 401-426. doi: 10.1146/annurev-pharmtox-011112140320

Ma, Q., Khatibi, N. H., Chen, H., Tang, J., and Zhang, J. H. (2011). History of preclinical models of intracerebral hemorrhage. Acta Neurochir. Suppl. 111, 3-8. doi: 10.1007/978-3-7091-0693-8_1

Maclellan, C. L., Silasi, G., Auriat, A. M., and Colbourne, F. (2010). Rodent models of intracerebral hemorrhage. Stroke 41, S95-S98. doi: 10.1161/STROKEAHA.110.594457
Mandolesi, G., Gentile, A., Musella, A., Fresegna, D., De Vito, F., Bullitta, S., et al. (2015). Synaptopathy connects inflammation and neurodegeneration in multiple sclerosis. Nat. Rev. Neurol. 11, 711-724. doi: $10.1038 /$ nrneurol.2015.222

Marti, H. H., and Risau, W. (1999). Angiogenesis in ischemic disease. Thromb. Haemost. 82(Suppl. 1), 44-52. doi: 10.1055/s-0037-1615552

Mehta, S. L., Manhas, N., and Raghubir, R. (2007). Molecular targets in cerebral ischemia for developing novel therapeutics. Brain Res. Rev. 54, 34-66. doi: 10.1016/j.brainresrev.2006.11.003

Mennel, H. D. (2000). [Mechanisms of angiogenesis in the brain]. Strahlenther. Onkol. 176, 46-47.

Mohanan, P., Subramaniyam, S., Mathiyalagan, R., and Yang, D. C. (2018). Molecular signaling of ginsenosides Rb1, Rg1, and $\mathrm{Rg} 3$ and their mode of actions. J. Ginseng. Res. 42, 123-132. doi: 10.1016/j.jgr.2017.01.008

Nabavi, S. F., Sureda, A., Habtemariam, S., and Nabavi, S. M. (2015). Ginsenoside Rd and ischemic stroke; a short review of literatures. J. Ginseng. Res. 39, 299-303. doi: 10.1016/j.jgr.2015.02.002

Naidu, S., Vijayan, V., Santoso, S., Kietzmann, T., and Immenschuh, S. (2009). Inhibition and genetic deficiency of p38 MAPK up-regulates heme oxygenase-1 gene expression via Nrf2. J. Immunol. 182, 7048-7057. doi: 10.4049/jimmunol.0900006

Oh, J., and Kim, J. S. (2016). Compound K derived from ginseng: neuroprotection and cognitive improvement. Food Funct. 7, 4506-4515. doi: 10.1039/C6FO01077F

Ong, W. Y., Farooqui, T., Koh, H. L., Farooqui, A. A., and Ling, E. A. (2015). Protective effects of ginseng on neurological disorders. Front. Aging Neurosci. 7:129. doi: 10.3389/fnagi.2015.00129

Orrenius, S., Gogvadze, V., and Zhivotovsky, B. (2007). Mitochondrial oxidative stress: implications for cell death. Annu. Rev. Pharmacol. Toxicol. 47, 143-183. doi: 10.1146/annurev.pharmtox.47.120505.105122

Ostrowski, R. P., Stepien, K., Pucko, E., and Matyja, E. (2016). Hyperbaric oxygen modalities are differentially effective in distinct brain ischemia models. Med. Gas Res. 6, 39-47. doi: 10.4103/2045-9912.179344

Park, E. K., Choo, M. K., Oh, J. K., Ryu, J. H., and Kim, D. H. (2004). Ginsenoside Rh2 reduces ischemic brain injury in rats. Biol. Pharm. Bull. 27, 433-436. doi: 10.1248/bpb.27.433

Park, H. J., Shim, H. S., Kim, K. S., and Shim, I. (2011). The protective effect of black ginseng against transient focal ischemia-induced neuronal damage in rats. Korean J. Physiol. Pharmacol. 15, 333-338. doi: 10.4196/kjpp.2011.15.6.333

Park, J. S., Shin, J. A., Jung, J. S., Hyun, J. W., Van Le, T. K., Kim, D. H., et al. (2012). Anti-inflammatory mechanism of compound $\mathrm{K}$ in activated microglia and its neuroprotective effect on experimental stroke in mice. J. Pharmacol. Exp. Ther. 341, 59-67. doi: 10.1124/jpet.111.189035

Park, S. I., Jang, D. K., Han, Y. M., Sunwoo, Y. Y., Park, M. S., Chung, Y. A., et al. (2010). Effect of combination therapy with sodium ozagrel and panax ginseng on transient cerebral ischemia model in rats. J. Biomed. Biotechnol. 2010:893401. doi: 10.1155/2010/893401

Peng, L., Sun, S., Xie, L. H., Wicks, S. M., and Xie, J. T. (2012). Ginsenoside Re: pharmacological effects on cardiovascular system. Cardiovasc. Ther. 30, e183-e188. doi: 10.1111/j.1755-5922.2011.00271.x

Prabhakaran, S., Ruff, I., and Bernstein, R. A. (2015). Acute stroke intervention: a systematic review. JAMA 313, 1451-1462. doi: 10.1001/jama.2015.3058

Raghunath, A., Sundarraj, K., Nagarajan, R., Arfuso, F., Bian, J., Kumar, A. P., et al. (2018). Antioxidant response elements: discovery, classes, regulation and potential applications. Redox Biol. 17, 297-314. doi: 10.1016/j.redox.2018.05.002

Rastogi, V., Santiago-Moreno, J., and Doré, S. (2014). Ginseng: a promising neuroprotective strategy in stroke. Front. Cell Neurosci. 8:457. doi: 10.3389/fncel.2014.00457

Rodrigo, R., Fernandez-Gajardo, R., Gutierrez, R., Matamala, J. M., Carrasco, R., Miranda-Merchak, A., et al. (2013). Oxidative stress and pathophysiology of ischemic stroke: novel therapeutic opportunities. CNS Neurol. Disord. Drug Targets 12, 698-714. doi: 10.2174/1871527311312050015

Romano, J. G., and Sacco, R. L. (2015). Decade in review-stroke: progress in acute ischaemic stroke treatment and prevention. Nat. Rev. Neurol. 11, 619-621. doi: 10.1038/nrneurol.2015.199

Sandercock, P., Wardlaw, J. M., Lindley, R. I., Dennis, M., Cohen, G., Murray, G., et al. (2012). The benefits and harms of intravenous thrombolysis with 
recombinant tissue plasminogen activator within $6 \mathrm{~h}$ of acute ischaemic stroke (the third international stroke trial [IST-3]): a randomised controlled trial. Lancet 379, 2352-2363. doi: 10.1016/S0140-6736(12)60768-5

Saver, J. L., Goyal, M., Bonafe, A., Diener, H. C., Levy, E. I., Pereira, V. M., et al. (2015). Stent-retriever thrombectomy after intravenous t-PA vs. $t$-PA alone in stroke. N. Engl. J. Med. 372, 2285-2295. doi: 10.1056/NEJMoa1415061

Seto, S. W., Chang, D., Jenkins, A., Bensoussan, A., and Kiat, H. (2016). Angiogenesis in ischemic stroke and angiogenic effects of Chinese herbal medicine. J. Clin. Med. 5, 56-71. doi: 10.3390/jcm5060056

Shen, Q., and Duong, T. Q. (2008). Quantitative prediction of ischemic stroke tissue fate. NMR Biomed. 21, 839-848. doi: 10.1002/nbm.1264

Shergis, J. L., Di, Y. M., Zhang, A. L., Vlahos, R., Helliwell, R., Ye, J. M., et al. (2014). Therapeutic potential of Panax ginseng and ginsenosides in the treatment of chronic obstructive pulmonary disease. Complement Ther. Med. 22, 944-953. doi: 10.1016/j.ctim.2014.08.006

Shibata, S., Fujita, M., Itokawa, H., Tanaka, O., and Ishii, T. (1963). Studies on the constituents of Japanese and Chinese crude drugs. Xi. panaxadiol, a sapogenin of ginseng Roots. Chem. Pharm. Bull. 11, 759-761. doi: 10.1248/cpb.11.759

Shin, K. C., Choi, H. Y., Seo, M. J., and Oh, D. K. (2015). Compound K production from red ginseng extract by beta-glycosidase from Sulfolobus solfataricus Supplemented with alpha-L-arabinofuranosidase from Caldicellulosiruptor saccharolyticus. PLoS ONE 10:e0145876. doi: 10.1371/journal.pone.0145876

Sims, N. R., and Muyderman, H. (2010). Mitochondria, oxidative metabolism and cell death in stroke. Biochim. Biophys. Acta 1802, 80-91. doi: 10.1016/j.bbadis.2009.09.003

Sinha, N., and Dabla, P. K. (2015). Oxidative stress and antioxidants in hypertension-a current review. Curr. Hypertens Rev. 11, 132-142. doi: 10.2174/1573402111666150529130922

Smith, I., Williamson, E. M., Putnam, S., Farrimond, J., and Whalley, B. J. (2014). Effects and mechanisms of ginseng and ginsenosides on cognition. Nutr. Rev. 72, 319-333. doi: 10.1111/nure.12099

Sofroniew, M. V. (2014). Multiple roles for astrocytes as effectors of cytokines and inflammatory mediators. Neuroscientist 20, 160-172. doi: $10.1177 / 1073858413504466$

Sofroniew, M. V. (2015). Astrocyte barriers to neurotoxic inflammation. Nat. Rev. Neurosci. 16, 249-263. doi: 10.1038/nrn3898

Song, L., Xu, M. B., Zhou, X. L., Zhang, D. P., Zhang, S. L., and Zheng, G. Q. (2017). A preclinical systematic review of ginsenoside-Rg1 in experimental Parkinson's disease. Oxid. Med. Cell Longev. 2017:2163053. doi: 10.1155/2017/2163053

Sotaniemi, E. A., Haapakoski, E., and Rautio, A. (1995). Ginseng therapy in non-insulin-dependent diabetic patients. Diabetes Care 18, 1373-1375. doi: $10.2337 /$ diacare.18.10.1373

Sun, C., Lai, X., Huang, X., and Zeng, Y. (2014a). Protective effects of ginsenoside Rg1 on astrocytes and cerebral ischemic-reperfusion mice. Biol. Pharm. Bull. 37, 1891-1898. doi: 10.1248/bpb.b14-00394

Sun, J. H., Tan, L., and Yu, J. T. (2014b). Post-stroke cognitive impairment: epidemiology, mechanisms and management. Ann. Transl. Med. 2:80. doi: 10.3978/j.issn.2305-5839.2014.08.05

Sun, M., Ye, Y., Xiao, L., Duan, X., Zhang, Y., and Zhang, H. (2017). Anticancer effects of ginsenoside Rg3 (Review). Int. J. Mol. Med. 39, 507-518. doi: 10.3892/ijmm.2017.2857

Sun, Y., Liu, Y., and Chen, K. (2016). Roles and mechanisms of ginsenoside in cardiovascular diseases: progress and perspectives. Sci. China Life Sci. 59, 292-298. doi: 10.1007/s11427-016-5007-8

Tang, B., Wang, D., Li, M., Wu, Q., Yang, Q., Shi, W., et al. (2017). An in vivo study of hypoxia-inducible factor-1alpha signaling in ginsenoside Rg1mediated brain repair after hypoxia/ischemia brain injury. Pediatr. Res. 81, 120-126. doi: 10.1038/pr.2016.178

Tasker, R. C., and Duncan, E. D. (2015). Focal cerebral ischemia and neurovascular protection: a bench-to-bedside update. Curr. Opin. Pediatr. 27, 694-699. doi: 10.1097/MOP.0000000000000287

Traystman, R. J. (2003). Animal models of focal and global cerebral ischemia. ILAR J. 44, 85-95. doi: 10.1093/ilar.44.2.85

Tu, J., Zhang, X., Zhu, Y., Dai, Y., Li, N., Yang, F., et al. (2015). Cell-permeable peptide targeting the Nrf2-keap1 interaction: a potential novel therapy for global cerebral ischemia. J. Neurosci. 35, 14727-14739. doi: 10.1523/JNEUROSCI.1304-15.2015
Unschuld, P. U. (1985). Medicine in China: A History of Ideas. Oakland, CA: University of California Press.

Wang, C. Z., Anderson, S., Du, W., He, T. C., and Yuan, C. S. (2016a). Red ginseng and cancer treatment. Chin. J. Nat. Med. 14, 7-16. doi: 10.1186/s13020-019-0231-3

Wang, D., Qiao, J., Zhao, X., Chen, T., and Guan, D. (2015). Thymoquinone inhibits IL-1beta-induced inflammation in human osteoarthritis chondrocytes by suppressing NF-kappaB and MAPKs signaling pathway. Inflammation 38, 2235-2241. doi: 10.1007/s10753-015-0206-1

Wang, L., Zhao, H., Zhai, Z. Z., and Qu, L. X. (2018a). Protective effect and mechanism of ginsenoside Rgl in cerebral ischaemia-reperfusion injury in mice. Biomed. Pharmacother. 99, 876-882. doi: 10.1016/j.biopha.2018.01.136

Wang, P., Shao, B. Z., Deng, Z., Chen, S., Yue, Z., and Miao, C. Y. (2018b). Autophagy in ischemic stroke. Prog. Neurobiol. 163-164, 98-117. doi: 10.1016/j.pneurobio.2018.01.001

Wang, Q. Y., Liu, F., Wu, F. J., and Li, J. L. (2013a). [Effects of ginsenoside Rg1 on the expressions of p-eRK1/2 and p-JNK in local cerebral ischemia/reperfusion injury rats]. Zhongguo Zhong Xi Yi Jie He Za Zhi 33, 229-234.

Wang, R., Wang, G. J., Wu, X. L., Zhou, F., and Li, Y. N. (2013b). Ginsenoside Rg1 attenuates structural disruption of the blood-brain barrier to protect the central nervous system in ischemia/reperfusion. Chin. J. Nat. Med. 11, 30-37. doi: 10.3724/SP.J.1009.2013.00030

Wang, Y., Yang, G., Gong, J., Lu, F., Diao, Q., Sun, J., et al. (2016b). Ginseng for Alzheimer's disease: a systematic review and meta-analysis of randomized controlled trials. Curr. Top Med. Chem. 16, 529-536. doi: $10.2174 / 1568026615666150813143753$

Ward, N. S. (2017). Restoring brain function after stroke - bridging the gap between animals and humans. Nat. Rev. Neurol. 13, 244-255. doi: 10.1038/nrneurol.2017.34

Wu, H., Niu, H., Wu, C., Li, Y., Wang, K., Zhang, J., et al. (2016). The autophagy-lysosomal system in subarachnoid haemorrhage. J. Cell Mol. Med. 20, 1770-1778. doi: 10.1111/jcmm.12855

Xie, C. L., Li, J. H., Wang, W. W., Zheng, G. Q., and Wang, L. X. (2015). Neuroprotective effect of ginsenoside-Rg1 on cerebral ischemia/reperfusion injury in rats by downregulating protease-activated receptor-1 expression. Life Sci. 121, 145-151. doi: 10.1016/j.lfs.2014.12.002

Xie, Z., Shi, M., Zhang, C., Zhao, H., Hui, H., and Zhao, G. (2016). Ginsenoside $\mathrm{Rd}$ protects against cerebral ischemia-reperfusion injury via decreasing the expression of the NMDA receptor 2B subunit and its phosphorylated product. Neurochem. Res. 41, 2149-2159. doi: 10.1007/s11064-016-1930-0

Xiong, Y., Mahmood, A., and Chopp, M. (2010). Angiogenesis, neurogenesis and brain recovery of function following injury. Curr. Opin. Investig. Drugs $11,298-308$.

Yamamoto, M., Kensler, T. W., and Motohashi, H. (2018). The KEAP1NRF2 system: a thiol-based sensor-effector apparatus for maintaining redox homeostasis. Physiol. Rev. 98, 1169-1203. doi: 10.1152/physrev.00023.2017

Yang, C. X., Liu, J. X., Sun, Z. L., Gao, X. Q., Deng, L., and Yuan, Q. L. (2008). [Effects of Ginsenoside RB1 on neural cell apoptosis and expressions of $\mathrm{Bcl}-2$ and $\mathrm{Bax}$ in rats following subjected to cerebral ischemia-reperfusion]. Sichuan Da Xue Xue Bao Yi Xue Ban 39, 214-217.

Yang, L. X., Zhang, X., and Zhao, G. (2016). Ginsenoside Rd attenuates DNA damage by increasing expression of DNA glycosylase endonuclease VIIIlike proteins after focal cerebral ischemia. Chin. Med. J. 129, 1955-1962. doi: 10.4103/0366-6999.187851

Yang, M. S., and Wu, M. (2016). Chinese Ginseng in Nutraceuticals, ed E. C. Gupta. San Diego, CA: Elsevier Inc., 693-705.

Yang, N., Chen, P., Tao, Z., Zhou, N., Gong, X., Xu, Z., et al. (2012). Beneficial effects of ginsenoside-Rg1 on ischemia-induced angiogenesis in diabetic mice. Acta Biochim. Biophys. Sin. 44, 999-1005. doi: 10.1093/abbs/gms092

Yang, X. D., Yang, Y. Y., Ouyang, D. S., and Yang, G. P. (2015a). A review of biotransformation and pharmacology of ginsenoside compound K. Fitoterapia 100, 208-220. doi: 10.1016/j.fitote.2014.11.019

Yang, Y., Li, X., Zhang, L., Liu, L., Jing, G., and Cai, H. (2015b). Ginsenoside Rg1 suppressed inflammation and neuron apoptosis by activating PPARgamma/HO-1 in hippocampus in rat model of cerebral ischemiareperfusion injury. Int. J. Clin. Exp. Pathol. 8, 2484-2494. 
Ye, R., Kong, X., Yang, Q., Zhang, Y., Han, J., Li, P., et al. (2011a). Ginsenoside rd in experimental stroke: superior neuroprotective efficacy with a wide therapeutic window. Neurotherapeutics 8, 515-525. doi: 10.1007/s13311-011-0051-3

Ye, R., Kong, X., Yang, Q., Zhang, Y., Han, J., and Zhao, G. (2011b). Ginsenoside $\mathrm{Rd}$ attenuates redox imbalance and improves stroke outcome after focal cerebral ischemia in aged mice. Neuropharmacology 61, 815-824. doi: 10.1016/j.neuropharm.2011.05.029

Ye, R., Yang, Q., Kong, X., Han, J., Zhang, X., Zhang, Y., et al. (2011c). Ginsenoside Rd attenuates early oxidative damage and sequential inflammatory response after transient focal ischemia in rats. Neurochem Int 58, 391-398. doi: 10.1016/j.neuint.2010.12.015

Ye, R., Zhang, X., Kong, X., Han, J., Yang, Q., Zhang, Y., et al. (2011d). Ginsenoside $\mathrm{Rd}$ attenuates mitochondrial dysfunction and sequential apoptosis after transient focal ischemia. Neuroscience 178, 169-180. doi: 10.1016/j.neuroscience.2011.01.007

Ye, R., Zhao, G., and Liu, X. (2013). Ginsenoside Rd for acute ischemic stroke: translating from bench to bedside. Expert. Rev. Neurother. 13, 603-613. doi: 10.1586/ern.13.51

Yuan, Q. L., Yang, C. X., Xu, P., Gao, X. Q., Deng, L., Chen, P., et al. (2007). Neuroprotective effects of ginsenoside $\mathrm{Rb} 1$ on transient cerebral ischemia in rats. Brain. Res. 1167, 1-12. doi: 10.1016/j.brainres.2007.06.024

Zeynalov, E., Shah, Z. A., Li, R. C., and Doré, S. (2009). Heme oxygenase 1 is associated with ischemic preconditioning-induced protection against brain ischemia. Neurobiol. Dis. 35, 264-269. doi: 10.1016/j.nbd.2009.05.010

Zhang, B., Hata, R., Zhu, P., Sato, K., Wen, T. C., Yang, L., et al. (2006). Prevention of ischemic neuronal death by intravenous infusion of a ginseng saponin, ginsenoside $\mathrm{Rb}(1)$, that upregulates $\mathrm{Bcl}-\mathrm{x}(\mathrm{L})$ expression. J. Cereb. Blood Flow Metab. 26, 708-721. doi: 10.1038/sj.jcbfm.9600225

Zhang, B., Matsuda, S., Tanaka, J., Tateishi, N., Maeda, N., Wen, T. C., et al. (1998). Ginsenoside $\mathrm{Rb}(1)$ prevents image navigation disability, cortical infarction, and thalamic degeneration in rats with focal cerebral ischemia. J. Stroke Cerebrovasc. Dis. 7, 1-9. doi: 10.1016/S1052-3057(98)80015-3

Zhang, G., Liu, A., Zhou, Y., San, X., Jin, T., and Jin, Y. (2008a). Panax ginseng ginsenoside-Rg2 protects memory impairment via anti-apoptosis in a rat model with vascular dementia. J. Ethnopharmacol. 115, 441-448. doi: 10.1016/j.jep.2007.10.026

Zhang, G., Xia, F., Zhang, Y., Zhang, X., Cao, Y., Wang, L., et al. (2016). Ginsenoside $\mathrm{Rd}$ is efficacious against acute ischemic stroke by suppressing microglial proteasome-mediated inflammation. Mol. Neurobiol. 53, 2529-2540. doi: $10.1007 / \mathrm{s} 12035-015-9261-8$

Zhang, L., Virgous, C., and Si, H. (2017). Ginseng and obesity: observations and understanding in cultured cells, animals and humans. J. Nutr. Biochem. 44, 1-10. doi: 10.1016/j.jnutbio.2016.11.010

Zhang, X., Shi, M., Ye, R., Wang, W., Liu, X., Zhang, G., et al. (2014a). Ginsenoside $\mathrm{Rd}$ attenuates tau protein phosphorylation via the PI3K/AKT/GSK-3beta pathway after transient forebrain ischemia. Neurochem. Res. 39, 1363-1373. doi: $10.1007 / \mathrm{s} 11064-014-1321-3$
Zhang, Y., Lin, L., Liu, G. Y., Liu, J. X., and Li, T. (2014b). Pharmacokinetics and brain distribution of ginsenosides after administration of sailuotong. Zhongguo Zhong Yao Za Zhi 39, 316-321. doi: 10.4268/cjcmm20140230

Zhang, Y., Zhou, L., Zhang, X., Bai, J., Shi, M., and Zhao, G. (2012). Ginsenoside-Rd attenuates TRPM7 and ASIC1a but promotes ASIC2a expression in rats after focal cerebral ischemia. Neurol. Sci. 33, 1125-1131. doi: 10.1007/s10072-011-0916-6

Zhang, Y. F., Fan, X. J., Li, X., Peng, L. L., Wang, G. H., Ke, K. F., et al. (2008b). Ginsenoside Rg1 protects neurons from hypoxic-ischemic injury possibly by inhibiting Ca2+ influx through NMDA receptors and L-type voltage-dependent Ca2+ channels. Eur. J. Pharmacol. 586, 90-99. doi: 10.1016/j.ejphar.2007.12.037

Zhang, Y. G., and Liu, T. P. (1996). Influences of ginsenosides Rb1 and Rg1 on reversible focal brain ischemia in rats. Zhongguo Yao Li Xue Bao 17, 44-48.

Zheng, G. Q., Cheng, W., Wang, Y., Wang, X. M., Zhao, S. Z., Zhou, Y., et al. (2011). Ginseng total saponins enhance neurogenesis after focal cerebral ischemia. J. Ethnopharmacol. 133, 724-728. doi: 10.1016/j.jep.2010. 01.064

Zheng, Q., Bao, X. Y., Zhu, P. C., Tong, Q., Zheng, G. Q., and Wang, Y. (2017). Ginsenoside Rb1 for myocardial ischemia/reperfusion injury: preclinical evidence and possible mechanisms. Oxid. Med. Cell Longev. 2017:6313625. doi: $10.1155 / 2017 / 6313625$

Zhou, X. M., Cao, Y. L., and Dou, D. Q. (2006). Protective effect of ginsenosideRe against cerebral ischemia/reperfusion damage in rats. Biol. Pharm. Bull. 29, 2502-2505. doi: 10.1248/bpb.29.2502

Zhou, Y., Li, H. Q., Lu, L., Fu, D. L., Liu, A. J., Li, J. H., et al. (2014). Ginsenoside Rg1 provides neuroprotection against blood brain barrier disruption and neurological injury in a rat model of cerebral ischemia/reperfusion through downregulation of aquaporin 4 expression. Phytomedicine 21, 998-1003. doi: 10.1016/j.phymed.2013. 12.005

Zhu, J., Jiang, Y., Wu, L., Lu, T., Xu, G., and Liu, X. (2012). Suppression of local inflammation contributes to the neuroprotective effect of ginsenoside Rb1 in rats with cerebral ischemia. Neuroscience 202, 342-351. doi: 10.1016/j.neuroscience.2011.11.070

Conflict of Interest Statement: The authors declare that the research was conducted in the absence of any commercial or financial relationships that could be construed as a potential conflict of interest.

Copyright $\odot 2019$ Liu, Anderson, Fernandez and Doré. This is an open-access article distributed under the terms of the Creative Commons Attribution License (CC BY). The use, distribution or reproduction in other forums is permitted, provided the original author(s) and the copyright owner(s) are credited and that the original publication in this journal is cited, in accordance with accepted academic practice. No use, distribution or reproduction is permitted which does not comply with these terms. 